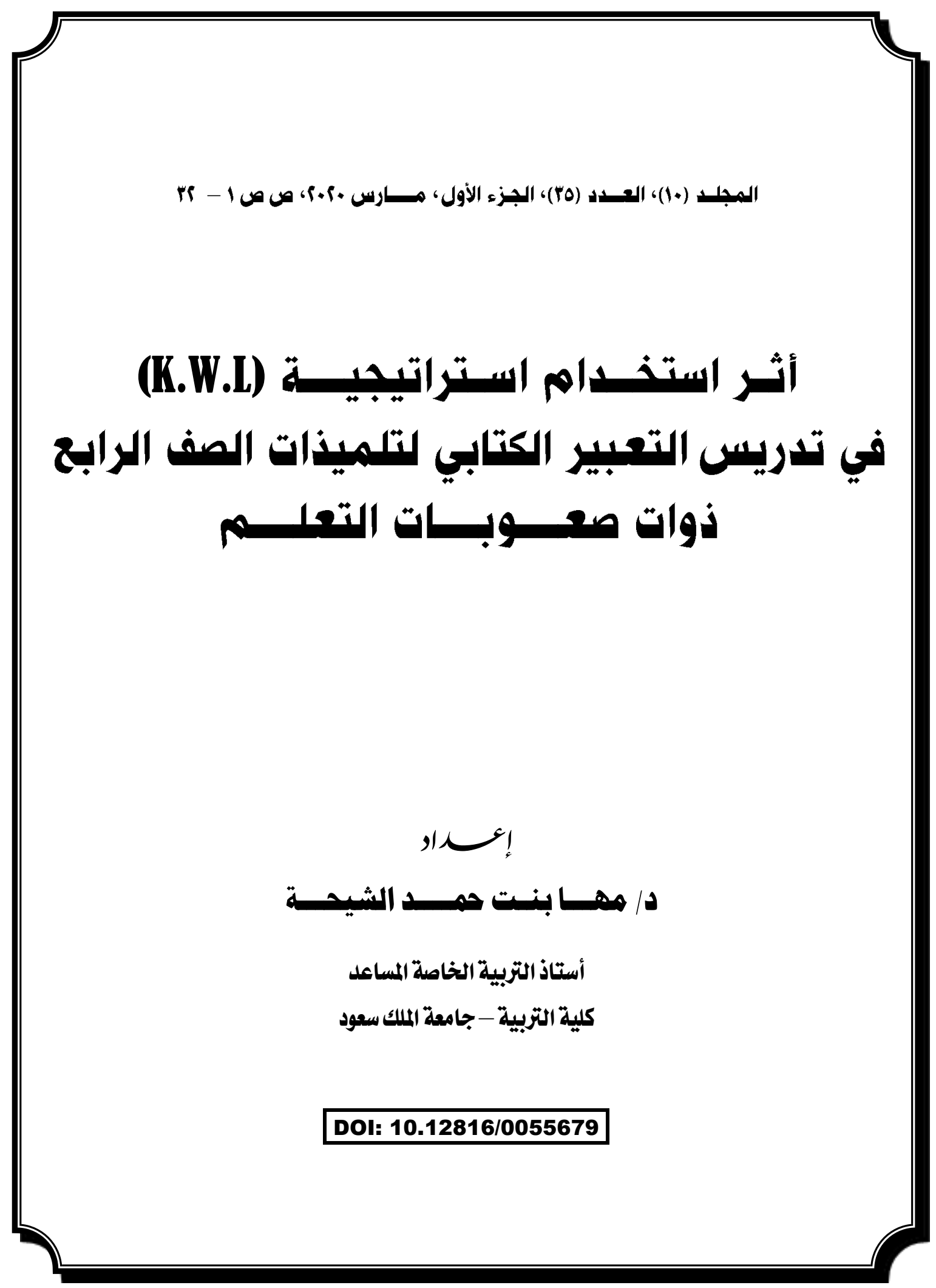




\section{أثر استخدام استزاتيجية [K.W.LI في تدريس التعبير الكتابي

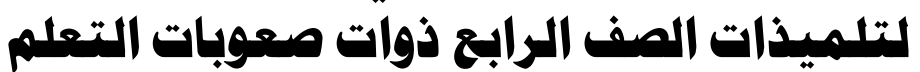 \\ ! إ}

د/ مهــا بنتت حمـلد الشيحــة (*)

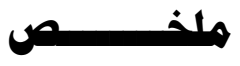

هدفت الدراسـة إلى التعرف على أثر التدريس باستخدام استراتيجية مـاذا اعرف: K، مـاذا

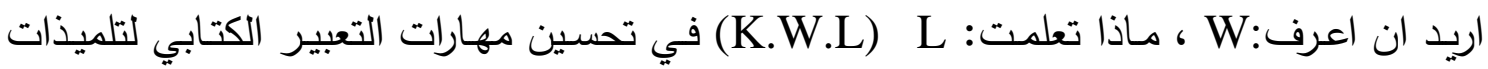
الصف الرابع ابتدائي. تألفت عينـة الدراسـة من (10) طالبة موزعة كالتالي: خمس تلميذات من ذوات صعوبات التعلم، خمس تلميذات من ذوات المستوى الضعيف في مهارات التعبير الكتابي، وخمس تلميذات من ذوات المستوى المتوسط. تم اختيار جميع التلميذات من صف دراسي واحد. طبق اختبار قبلي وبعدي على المجموعات الثلاث لقياس تحصيلهن. كان التركيز في اختبار الكتابة على عدد الجمل في النص، عدد المفردات في الجملة، والحصيلة الاجمالية للمفردات. تم تدريس المجموعات الثلاث معا ( • ع) حصة على مدى (• () أسابيع. اثناء تطبيق الاستراتيجية تم إعطاء ثلاثة اختبارات تجريبيـة لمتابعـة التقدم. أظهرت النتائج تحسن التلميذات ذوات صسعوبات التعلم في الدرجة الكلية لاختبار التعبير الكتابي وأبعاده الفرعية وذلك لصالح التطبيق البعدي، امـا عدد المفردات فرغم ارتفاع حصيلتهن اللغويـة فيه لكنه لم يكن دال احصـائيا. واسفرت النتائج عن عدم وجود فروقاً ذات دلالة إحصائية بين الدرجة الكلية للتميذات ذوات صعوبات التعلم والعاديين (منخفي التحصيل - متوسطي التحصيل) في الدرجة الكلية لاختبار التعبير الكتابي وأبعاده. الكلمات المفتاحية: استراتيجية (K.W.L)؛ التعبير الكتابي، صعوبات التعلم. 
د/ مها بنت حمد الشيحة أثر استذدام استراتيهية (K.W.L) في تدريس التعبير الكتابي لتلميذات الصف الرابع ذوات صعوبات التعلم

Using the [K.W.L] Strategy in Teaching Written Expression for Fourth-Grade Students with Learning Difficulties $\square$

\author{
By \\ Dr. Maha Al-Sheaha ${ }^{(*)} \square$
}

\title{
Abstract $\square$
}

The purpose of this study was to investigate the effectiveness of using the K.W.L. strategy in improving writing skills for fourth grade primary school students with learning disability (LD). The sample consisted of (15) female students. For research purpose they classify into 3 groups: LD, low skills level of writing expression (WE), and intermediate level. All students were selected from one class. A pre and post-test was applied to all groups to measure their achievement. The focus of the writing test was on: the number of sentences in the text, the number of words in the sentence, and the total proceeds of the vocabulary. Then they were taught together (40) lessons over (10) weeks. The results showed that there was statistically significant improvement of students with LD in the total score of the pre and post WE. As for the number of vocabulary, despite their increase, it was not statistically significant. In addition, there were no statistically significant differences between the mean scores of students with LD and ordinary students in the total score for the WE test.

Key words: (K.W.L) strategy, writing expression (WE), learning disability (LD).

(*) Assistant Professor, Department of Special Education, College of Education, King Saud University, Riyadh, Saudi Arabia. alsheaha@ksu.edu.sa

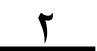


يحتل التعليم الابتدائي أهمية كبيرة في منظومة التعليم لأنه أسـاس للمراحل التي تليه. ومن أكثر المشكلات شيوعاً وانتشـاراً وسط تلاميذ المرحلة الابتدائية ضعف التعبير الكتابي (شعبان، (1 • ( )، حيث يعتبر التعبير الكتابي من اعقد المهارات المدرسية؛ فالإنسان يصوغ افكاره برسائل مكتوبـة للآخرين بشكل واضـح لإيصـال هذه المعلومات. مهارة التعبير تتطلب من الكاتب اتقان مهارات اللغة الأخرى كالإملاء والخط بمستوى فوق المتوسط، وتوفر حصيلة مفردات لغويـة جيدة

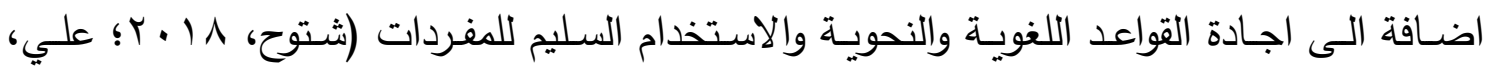
9 . . ب). فهو يعد اعلى مسـتوى مـن مراحل تعلم اللغـة لأنـه يأتي بعد تعلم مهارات الاسـتماع والتحدث والقراءة، فإذا وجد الطفل صسوبة في اكتساب المهارات الثلاث الأولى، فإنـه في الغالب سيواجه صعوبة في تعلم الكتابة أيضا. وقد أجريت عدد من الدراسات عن التعبير الكتابي في مدارس المملكة العربية السعودية،

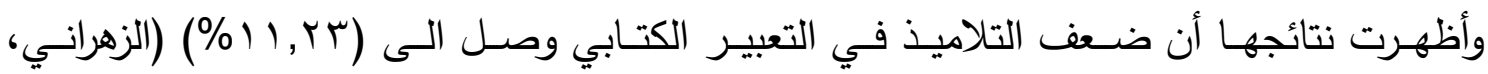
11 ( ا ) ويعتبر أكبر من ضعفهم في الإملاء والنحو. وأن درجة تحقق الأهداف المرجوة من تدريس التعبير الكتابي تتراوح بين المتوسطة والقليلة، وتوظيف معلمي المرحلة الابتدائية لمهارات التعبير

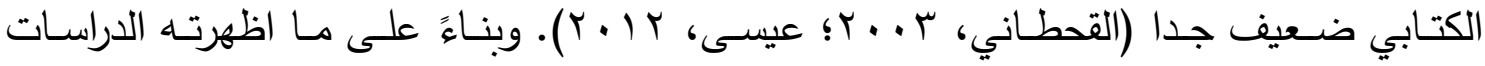

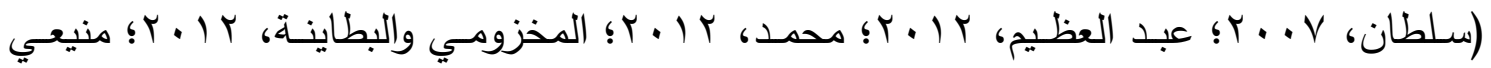

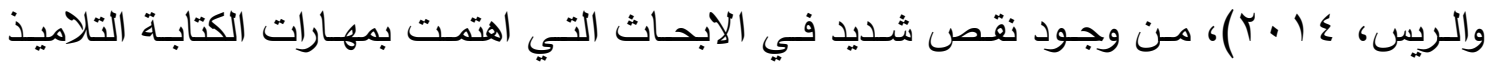
العاديين، فان الاحتياج اشد مع التلاميذ ذوي صعوبات التعلم في التعبير •

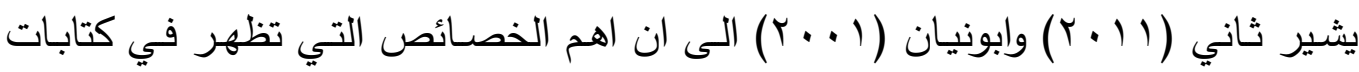
التلاميذ الين يعـانون من صعوبات تعلم التعبير الكتابي هي: قصر الفقرات، قلة الافكار وعدم ترابطها منطقيا، ضعف المفردات اللغويـة المستخدمة مما نتج عنه صعوبـة في التخطيط للكتابـة وتوليد الافكار وترتيبها بشكل سلس. من المشـاكل المنتشرة بينهم ايضـا صعوبة تحديد الافكار الرئيسية والتوضيحية او الفرعية، كما يغفلون المراجعة والتصحيح الذاتي. ولديهم صعوبة في اليات 
الكتابة كالإملاء والخط وسرعة الكتابة؛ وهي تثكل عقبة كبرى امامهم لتسبيها بانخفاض المرونة في الكتابة. ذكر (Vogel, 1998) ان التلاميذ ذوي صعوبات التعلم يختلفون عن اقرانهم العاديين في: ضـفف معـرفتهم باستراتيجيات الكتابـة، قلـة وعيهم بخطوات الكتابـة، وانخفاض الحصيلة المعرفية لديهم لذا يغلب على كتاباتهم قصر الموضوع، قلـة عدد الجمل والمفردات المستخدمة،

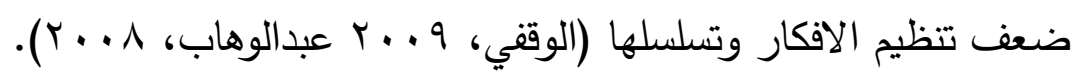

مهارة الكتابة إحدى المهارات الأكاديمية الأساسية التي يجب أن يتم الاهتمام بها في المدرسة الابتدائية لأنها: تثكل مدخلا للتعلم، كما أن تركيز المعلمين ينصب عليها كوسيلة للتقييم، لذا فالتلميذ يحتاجها لتحقيق النجاح في المواد الدراسية والحصول على الثهادة. ولا ننكر تأثيرها على مستقبل الفرد لاحقا أكاديميا ومهنيا واجتماعيا. رغم اهمية هذه المهارات فان الدراسات باللغة العربية فيها قليلة وقد يكون ذلك ناتج عن ان مهارات التعبير الكتابي متعددة ومتثعبة ويصعب تقييمها.

أنَّ ميدان صـوبات التعلم يفتقر على مستوى الممارسـات التعليميـة إلى بعض البرامج

والاستراتيجيات التي تساعد في تتمية وتطوير مهارات التعبير الكتابي لدى التلاميذ ذوي صعوبات التعلم، إذْ إنهم يعانون من ضعف في الكتابة بشكل عام وفي مهارات التعبير الكتابي بشكل خاص. فهنالك حاجـة ماسـه الى بنـاء بـرامج علاجيـة تعتمد على اسـتراتيجيات تتناسب مـع خصـائص المتعلمين ومتطلبات التعبير الكتابي. من الاستراتيجيات المستخدمة في الدول الاخرى استراتيجية (Tok, 2013) كما انها تهدف الى مساعدة التلاميذ على تحسين الفهم العميق لموضوع النقاش، وتساهم في تشكيل المفاهيم بالتحليل والدراسة (Zouhor, Jaskov and Bogdanovic, 2016) وتمكن المعلمين من مراقبة التطور المعرفي

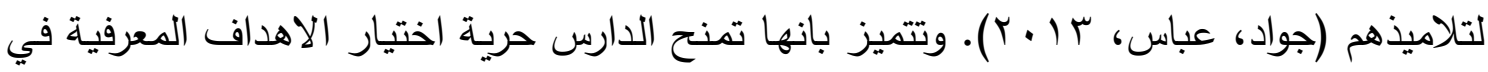
2019) Lupo, Tortorelli, حدود الموضوع مما يسهم في بناء مهاراته غير اكاديمية. دراسة (Invernizzi， Ryoo， Strong الاستراتيجيات في تدريس التلاميذ ذوي التحصيل المنخفض في التعبير الكتابي. 
لذا تهدف الدراسة الحالية الى بحث أثر استخدام استراتيجية (KWL) مع التلاميذ ذوي صعوبات التعلم لاكتسابهم مهارات التعبير الكتابي مقارنة بأقرانهم العاديين. ولإجابة هذا السؤال تم

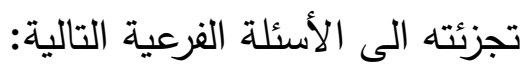
هل توجد فروق ذات دلالة احصائية بين درجات القياس القبلي والبعدي للتلميذات ذوات

$$
\text { صعوبات التعلم بعد تدريهم باستخدام استراتيجية (KWL)؟ }
$$

هل توجد فروق ذات دلالة احصائية بين درجات القياس القبلي والبعدي بين للتلميذات العاديات

(ذوات الاداء الضعيف، ذوات الاداء المتوسط) بعد تدريسم باستخدام استراتيجية (KWL)؟

هل توجد فروق ذات دلالة احصائية بين درجات القياس البعدي بين المجموعات الثلاث؟

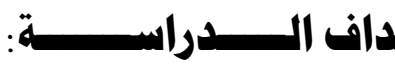

تهـدف الدراسـة الحاليـة إلـى استقصــاء أثر تـدريس مهارات التعبيـر الكتابي باسـتخدام استراتيجية K.W.L. لتلميـات الصفف الرابع ابتدائي ذوات صسعوبات الـتعلم مقارنــة بقرينتهن العاديات من المستوى الضـعيف والمتوسط، من حيث المتطلبات الكتابيـة التالية: عدد الكلمـات المستخدمة في الجملة الواحدة، عدد الجمل، عدد الكلمات المستخدمة في المقطع الكتابي، وهل يوجد ترابط بين الجمل؟ هل الكلمات مرتبة بطريقة صحيحة داخل الجملة لتعطي معنى؟ هل تعبر الفكرة الأساسية عن الموضوع؟ هل الأفكار الفرعية تدعم الفكرة الأساسية؟

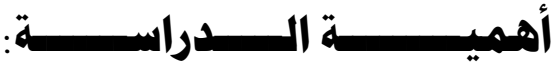

يتوقع لهذه الدراسة ان تظهر اهميتها للتلاميذ، والمعلمين، والمخططين والباحثين. ويمكن تقسيم أهميتها الى نظرية وتطبيقية. الأهمية النظرية تتمثل في انها من المتوقع ان تساعد واضعي المناهج في بناء منهج أكثر ملائمة لتدريس التعبير الكتابي في المرحلة الابتدائية مع الاخذ بعين الاعتبار التكييفات اللازمة لذوي صعوبات التعلم. كما يمكن الاستفادة من نتائج الدراسة الحالية في دراسات مستقبلية مفيدة من الناحية العلمية والتطبيقية. اما الأهمية التطبيقية فهي مساعدة المعلمين على التعرف على الاخطـاء اللغويـة الثـائعة للى تلاميذ الصف الرابع وخاصـة ذوات صـوبات التعلم، وامكانية الاستفادة منها عند تخطيط دروس اللغة العربية. 


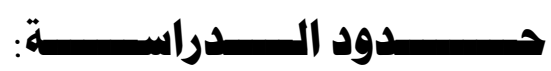

تقتصر حدود الدراسة الموضوعية على تتاولها أثر استخدام استراتيجية (KWL) لتحسين مهارات التعبيـر الكتابي لطالبـات الصفف الرابـع ابتدائي بمدرسـة ابتدائيـة بمدينـة الريـاض، خـلال

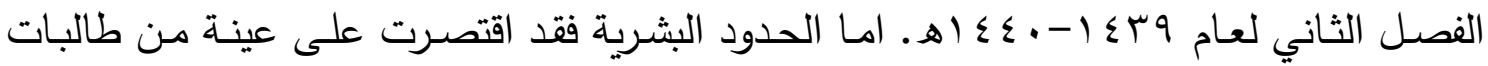
الصف الرابع الملتحقات ببرامج ذوي صسوبات التعلم، وطالبات عاديات من المستوى المنخفض والمتوسط وفقا للرجاتهن السابقة، وكانت العينة من الاناث فقط.

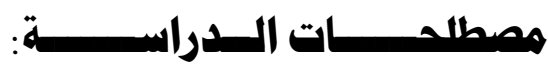

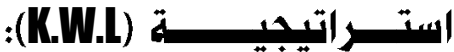

من الاستراتيجيات فوق المعرفية التي تتكون من ثـلاث خطوات: ما أعرفه - مـا أريد أن أعرفهـ - مـا تعلمتهـ (Alsoudi1, 2017, 33) صـمدت لتتشيط المعرفـة الأساسية للتلاميذ، ولمساعدتهم على فهم ما قرأوه (İlter, İlhan, 2018) ( التعريف الاجرائي: خطوات منظمة يقوم بها التلميذ تعتمد على استدعاء معارف سابقة، وتحدد تساؤلاته والوعي بما تم تعلمه كتابيا.

التلامهذ ذوو صعوبات: "هم الذين يعانون من ضـف أكاديمي واضـح، ويتلقون خدمات التربية الخاصـة في برامج صعوبات التعلم في المدرسة العادية بعد تشخيصهم والتعرف عليهم"(البتال، س ا ـ ب، سب).

\section{صعوبات التعبير الكتابي:}

ضعف قدرة التلميذ على ترجمة الافكار الى كتابة بدرجة تجعله أقل من اقرانـه ممن هم في

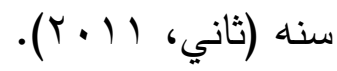
التعريف الإجرائي: ضـفف قدرة التلميذ على إيصـال أفكاره ومعارفهه بطريقـة مكتوبـة لمـن حوله مما يؤثر على حياته بشكل عام.

\section{التلاميذ العاديون:}

هم التلاميذ الذين لا يوجد لديهم احتياجات خاصـة، ولا يحتاجون لخدمات التربية الخاصـة

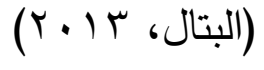




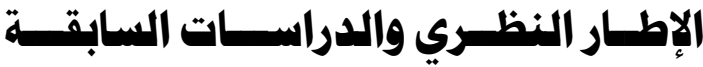

تستعرض الدراسـة محورين في الإطـار النظري: استراتيجية (KWL) وصعوبات التعبير

الكتابي. امـا بالنسـبة للدارسـات السـابقة فلم تتـوفر للباحثة دراسـات ذات علاقـة مباشـرة بالدراســة الحاليـة:" أثر استخدام استراتيجية (KWL) في تدريس التعبير الكتابي لطالبات الصف الرابع ابتدائي ذوات صـعوبات التعلم" لذلك تم عرض دراسـات ذات علاقة ببعض متغيراتها. في ضـوء اطلاع الباحثة على الدراسات ذات الصلة وجدت قلة في الدراسات العربية والاجنبية التي اهتمت بالموضـوع. كما لاحظت ان الدارسـات الاجنبيـة ضـنت التعبير الكتابي كأحد فروع اللغـة بشكل عام، ونـادرا مـا يتم تقريده بدراسـات مستقلة. لذا تم انتقاء بعض الدراسـات ذات العلاقة بالتعبير الكتابي لذوي صعوبات التعلم وسيتم استعراضها وفقا للتسلسل الزمني من الاقدم الى الاحدث.

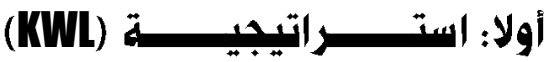
احدى اسـتراتيجيات تدريس المهارات فوق المعرفيـة والتـي يمكن اسـتخدامها في جميع المقررات الدراسية. ابتكرهـا Donna Ogle عـام (T/9 ()) وتتكون مـن ثلاث خطوات. يشسير اختصـار اسمها الى اول حرف من كل خطوة: Khat I Know? ماذا أعرف عن موضوع الدرس او النقاش. What I Want to Learn? :W ماذا أريد أن أتعلم عن هذا الموضوع. هذه الخطوة والخطوة الاولى تتم قبل بداء التعلم او الدرس، وتعدا مرحلتا تمهيد او تحضير للدرس المقدم. What I Learned? :L تعني ماذا تعلمت تتم هذه الخطوة في نهاية الدرس. تهدف هذه الاستراتيجية الى تنشيط معارف وخبرات التلاميذ السـابقة وربطها بالمعلومات الجديدة الواردة في

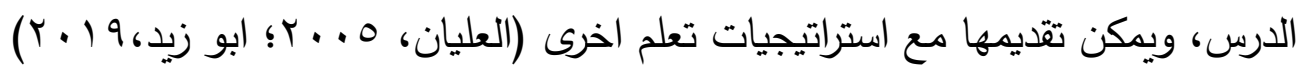
من الدراسات التي استخدمت هذه الاستراتيجية دراسة عليمات (1 ا • r)، التي هدفت الى بحث أثر استخدام هذه الاستراتيجية في اكتساب المفاهيم العلمية والاحتفاظ بها في مادة العلوم لتلاميذ الصف الثالث الأساسـي مقارنة بالطريقة التقليدية. تكونت عينـة الدراسـة من (q؟) تلميذا موزعين في مجموعتين ضـابطة وتجريبية. أظهرت نتائج الاختبار التحصيلي للتلاميذ ان التدريس باسـتخدام اسـتراتيجية (KWL) ذو دلالـه إحصـائية في اكسـاب المفـاهيم العلميـة والاحتفـاظ بهـا لصالح المجموعة التجريبية. 


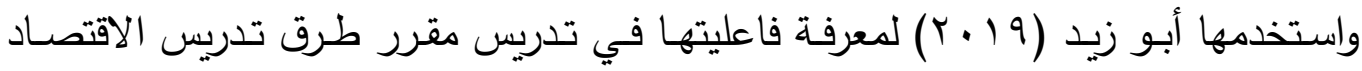

المنزلـي للطالبـات المعلمـات بجامعـة القصـيم. اسـتخدمت الباحثـة التصـميم التجريبـي على ؟ 7 مشـاركة. أظهرت النتائج فروق ذات دلالـة إحصـائية بين المجوعـة الضـابطة والتجريبيـة لصـالح التجربية في الاختبار المعرفي.

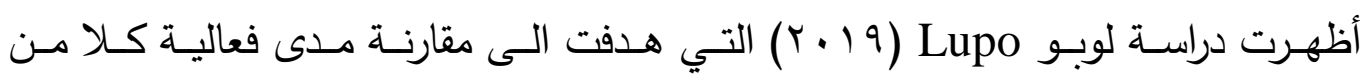
استراتيجية اسمع، اقراء، ناقش واستراتيجية (KWL) على تحسين الفهح القراءة لدى (rq ץ) مراهقا في الصف التاسع يعانون من مشاكل في القراءة. تم تقييم الفهم العام قبل وبعد التدخل باستخدام اختبار فهم القراءة غيتس - ماكجينييتي. كثفت النتائج أن فهم الطلاب المستخدم معهم استراتيجية فاق اقرانهم. تشير النتائج إلى أن معظم الطـلاب الذين يعانون من صعوبة في الفهم يمكنهم قراءة النصوص عندما يصاحبها دعم تعليمي.

\section{صعــــــات التعبــير الكتــــــي}

يعتمد التعبير الكتابي على قدرة التلاميذ على استرجاع الافكار التي تم تخزينها في اذهانهم وصياغتهم لها في شكل عبارات وجمل مترابطة مكتوبة تتم عن معتقداتهم ومشاعرهم. تنعكس قدرة الطالب الكتابية عن تعبيره لأفكاره بعبارات صحيحة سليمة خالية من الاخطاء الاملائية واللغويـة (النحـو والصـرف) بدرجـة تناسـب مسـتواه اللغوي مـع الدقـة في اختيـار الالفـاظ الملائمسة وتتسيق الافكار وترتيبها وجمعها وريطها ببعضـها (ثاني، (1) ( إ). كما لابد لله ان يقدم النص في شكل جمل وفقرات ذات طول ملانُم ويضـم مجموعـة مـن الافكار الواضـحة، مكتوب بخط مقروء مـع

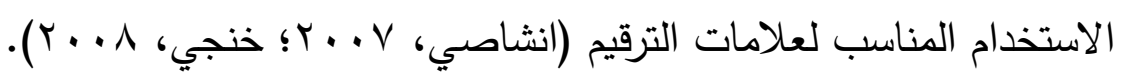

صسوبات التعبير الكتابي تظهر في شكل صسوبات في بناء وتركيب الجمل وتوظيف القواعد اللغويـة والنحويـة، وتتظيم الكلمـات في الجمل، وعدم الاستخدام السليم للأفعال والضمائر ، وعدم ترتيب حروف الكلمة، وقلة المفردات، وصعوبة استعادة الكلمة. أجرتُ غاون (Gaon, 2001) دراسة شارك فيها ستة عشر طالبا من ذوي صعوبات التعلم في المرحلة الثانوية هدفت إلى اختبار التعبير الثفوي والكتابي. قدم للطلبة متطلبين: الأول مكتوب 
والثاني شفوي. استخدام الباحث مقياس مشابه لما يستخدمه مدرسي اللغة الانجليزيـة في مدارس ولاية نيويورك الثانوية لتقييم واجبات الطلاب. سُجلت استجابات الطلاب اللفظية والمكتوبة. أظهرت النتائج أنَّ نوعية الاستجابات اللفظية لم تكن مقبولة، وأنَّ أداء الطلبة كان ضعيفاً في كلا الجانبين اللفظي والكتابي.

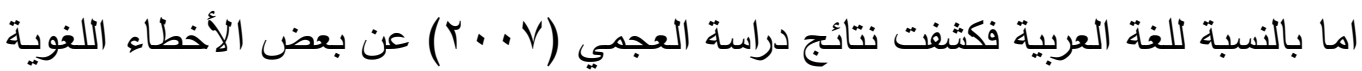

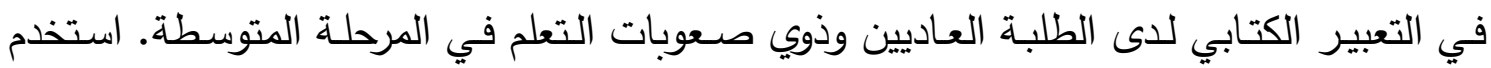
الباحث المنهج الوصفي مع ( · . ( ) طالب وطالبة، خمسين منهم من ذوي صعوبات التعلم. كثفت نتائج الدراسة ان هناك أخطاء لغوية لدى جميع الطلبة في جميع مجالات الاختبار مع اختلاف نسب الأخطاء، وكانت أخطاء الطلبة ذوي صعوبات التعلم أكثر من أخطاء العاديين في جميع

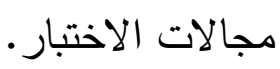

من جهة اخرى توجه بعض الباحثين الى دراسة أثر استخدام الاستراتيجيات في تحسين

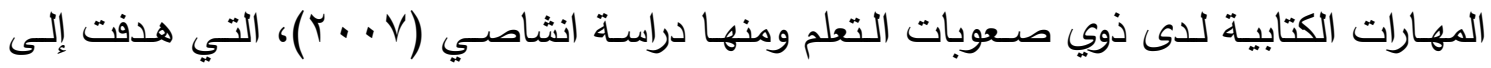
معرفة أثر استراتيجية تتظيم الذات على تتمية مهارة التعبير الكتابي لدى التلاميذ ذوي صعوبات التعلم من حيث كيفية الكتابة وكميتها. باستخدام المنهج التجريبي مع (• ـ تلميذا) من الصفين الخامس والسادس الابتدائي بالأردن. صممت الباحثة مقياس لتقييم العملية الكتابية. اسفرت النتائج عن فعالية الاستراتيجية في نوعية الكتابة وكميتها. بحثت دراسة كونراد وتيست (Konrad \& Test, 2007) تأثير برنامج (Go s it) على بلى قدرة التلاميذ في كتابة أهداف الخطة الفردية الخاصة بهم، وتأثيره على مهارات كتابة لديهم. وهو برنامج تدخل قائم على استراتيجية تنظيم الذات. وتكونت العينة من (ع تلميذات، 1 تلميذا) من ذوي صعوبات تعلم. تراوحت اعمار التلاميذ الزمنية ما بين (11- 1 (1) سنة. وتم قياس المتغيرات

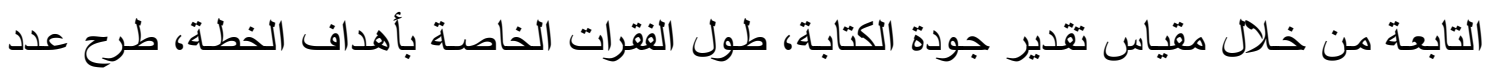
الكلمات المتتابعة الصحيحة من عدد الكلمات المتتابعة الخاطئة في الفقرات. وأثبتت النتائج تأثير البرنامج في تحسين قدرة التلاميذ على كتابة الفقرات الخاصـة بالبرنامج الفردي، وتحسين قدرتهم الكتابية بشكل عام. 
قام سادلر واخرون Saddler, Asaro, \& Behforooz (2008) بحثث أثر استخدام عملية تكوين الجمل بمساعدة الاقران في تتمية مهارات كتابة القصة لدى أربعة شباب يعانون من صعوبات التعلم في الكتابة. وجاءت نتائج الدراسة مؤكدة على ان استخدام تمارين تجميع الجمل تؤدي الى تحسين القدرة على بنائها، وتحسين مستوى جودة كتابة الطلاب للقصص، واستخدمه لعناصر بناء الجملة، وزيادة معدل مراجعتهم للقصص المكتوبة. اما دراسة فيل- روما (Viel- Ruma, 2008) فسعت إلى بحث العلاقة بين استخدام التدريس المباشـر وأداء الطـلاب ذوي صـعوبات التعبير الكتابي؛ سواء كـان هؤلاء الطـلاب مـن متعلمي اللغة الأصليين أو الأطفال الإسبان المتعلمين للغة الإنجليزية كلغة ثانية. وتكونت العينة من ثلاث طلاب من ذوي صعوبات التعبير الكتابي في اللغة الإنجليزيـة كلغة أولى، وثلاث طلاب التبلي من ذوي صسوبات التعبير الكتابي في اللغـة الإنجليزيـة كلغة ثانية. وأثشارت نتائج الدراسـة إلى تحسن الأداء لاى الطلاب ذوي صعوبات التعبير الكتابي سواء كانوا من متعلمي اللغة الإنجليزية كلغة أولى أو كلغة ثانية. عملت دراسة علي، صياح، الزيات (9 . . ب)، على معرفة ما إذا كان هناك فروق في ابعاد البنية المعرفية المتمثلة في التكامل والاتساق والكم والكيف بين التلاميذ ذوي صعوبات التعبير الكتابي والعاديين والمتفوقين في الصفين السادس الابتدائي والثاني الاعدادي بمملكة البحرين. اتبع البـاحثون المنهج الوصـفي، وشـارك في الدراسـة (OY I ) طالبا. بواقع (OV) من ذوي صـوبات التعلم، و ( ؟) من العاديين، و(ب0) من المتفوقين. وصلت نتائج الدراسة الى انه يوجد فروق دالة احصائيا بين ذوي صعوبات التعلم والعاديين في ابعاد البنية المعرفية لصالح العاديين. يمكن التنبؤ بصعوبات التعبير الكتابي من خلال ابعاد البنية المعرفية المتمثلة بالتكامل والاتساق والكم والكيف. بحثت دراسة ثاني (1) ب (1) التجريبية في المقارنة بين فعالية اسلوب تدريس الاستراتيجية والتدريس المباشر لتتمية مهارات التعبير الكتابي للطالبات ذوات صعوبات التعلم. تكونت عينـة

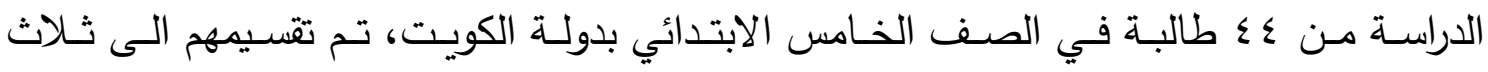
مجموعات. خلصت الدراسة الى وجود فروق دالة احصائياً بين درجات الاختبار القبلي والبعدي 
لللجموعتين اللتين تم تدريسها بأسلوب تدريس الاستراتيجية وبالأسلوب المباشر لصالح البعدي. عدم وجود فروق دالة احصائياً بين درجات الاختبار القبلي والبعدي للمجموعة التي تدرس بالطريقة التقليدية. وكذلك عدم وجود فروق دالة احصـئيا بين درجات المجموعتين التي تدرس بالتدريس المباشر والتي تدرس بأسلوب تدريس الاستراتيجية في الاختبار البعدي. اهتمت دراسة الخيواني (10 ب ب بتحديد مهارات الكتابة اللازمة لتلاميذ المرحلة الابتدائية في ضـوء تـدريب معلميهم على استراتيجية التدوين المزدوج. طبق الـنهج الوصفي التحليلي على(·r) تلميذا من ذوي صعوبات التعلم في المرحلـة الابتدائية بنجران. اعد الباحث: استبانة لتحديد مهارات الكتابة، استمارة تقييم كتابات التلاميذ ذوي صعوبات التعلم بالمرحلة الابتدائية، برنامج تطبيقي لاستراتيجية التدوين المزدوج لكي يطبقه المعلمون. المهارات الكتابية اللازمة لذوي صعوبات التعلم بالمرحلة الابتدائية تمثلت في: مهارات ترتبط بالمفردات، ومهارات ترتبط بالتركيب والأسلوب، ومهارات ترتبط بالأفكار ، ومهارات ترتبط بالتظيم، وتضم. وجد الباحث ان هناك تأثير دال لهذه الاستراتيجية في اكتساب مهارات الكتابة من قبل التلاميذ ذوي صعوبات التعليم، واتضح ذلك من خلال تحليل كتاباتهم.

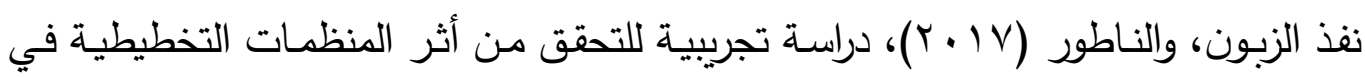
تطوير مهارات التعبير الكتابي لدى الطلبة ذوي صعوبات التعلم. شارك في العينة (•r) طالبا وطالبة من ذوي صعوبات التعلم في الصف الخامس الابتدائي في لواء قصبة المفرق. اظهرت النتائج وجود أثر ذي دلالـة إحصـائية لطريقة التدريس المستتدة إلى المنظمـات التخطيطية في تطوير مهارات التعبير الكتابي لمجال الثكل والمضمون في القياس البعدي لصالح المجموعة التجريبية. جرب محمد، ومكاوي، وجاب الله (V ا • Y)، عـلاج صعوبات التعبير الكتابي الإبداعي لطلاب الصف الأول الاعدادي باستخدام التعليم المنظم ذاتياً مع (•؛) طالبا في بنها بمصر . خلصت النتائج الى فعالية التعليم المنظم ذاتياً في علاج صعوبات التعبير الكتابي للى طلاب الصف الأول الاعدادي. 


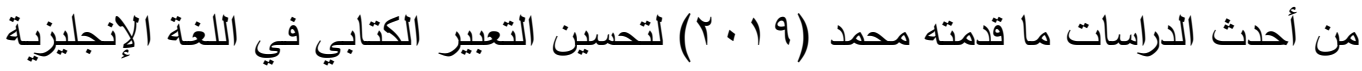

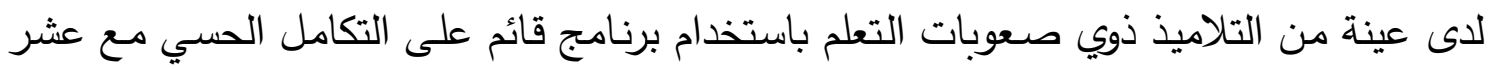

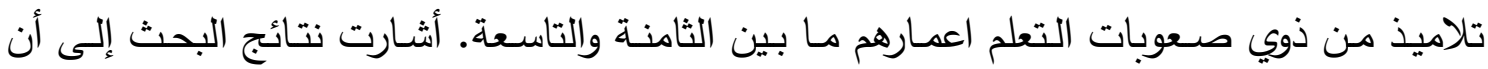

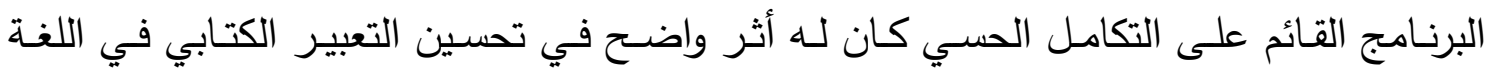
الإنجليزية لدى التلاميذ ذوي صعوبات التعلم. في ضوء ما تم مناقشته في الدراسات السابقة، يتضح ما يأتي: • أنَّ أداء التلاميذ ذوي صعوبات منافئه في التعلم كان ضعيفاً في التعبير اللفظي والكتابي.

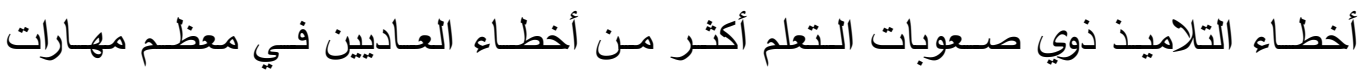
التعبير الكتابي. هاعلية استخدام الاستراتيجيات والبرامج في تتمية مهارة التعبير الكتابي لدى جميع التلاميذ.

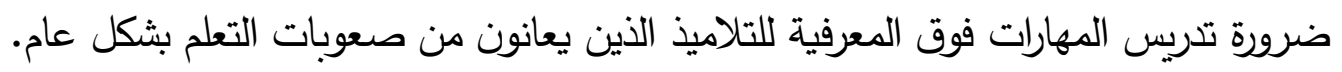
العلاقة القوية بين مهارات القراءة والتعبير الكتابي. ضرورة تسلسل مهارات تعليم التعبير الكتابي. ضرورة تدريب المعلمين على اساليب تدريس الاستراتيجيات الحديثة.

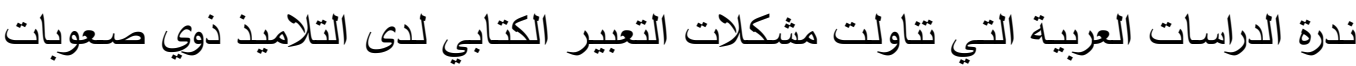
التعلم، وكذلك العاديين. يوجد اهتمام كبير بصعوبات التعبير الكتابي من جانب الباحثين في الدول الغربية. لذلك تتفق الدراسة الحالية في مناقثة هذه الصعوبات، ولكنها تختلف حيال ما تم ذكره في

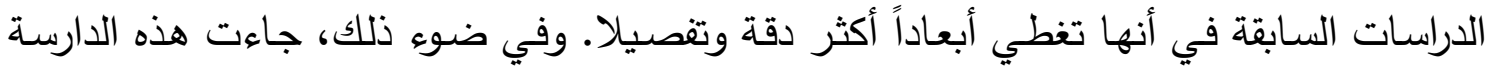
لتحديد أثر استخدام استراتيجية KWL في تطوير مهارات التعبير الكتابي.

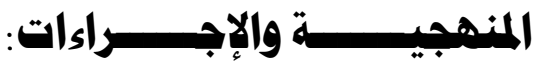

\section{منهـــة الــدراسـة}

استخدمت الدارسـة المنهج شـبه التجريبي واختارت (التصـميم قبلي ـ بعدي لمجموعـة

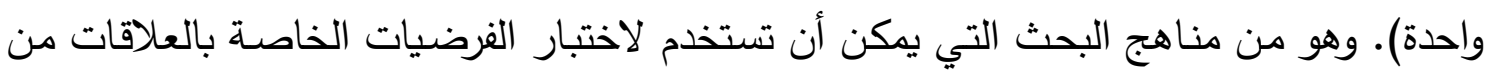
نوع سبب ونتيجة (عدس، (999 (1)). 


\section{مجتمع وعينة الاراسة}

تمثل مجتمـع الدراسـة المستهدف مـن جميع المدارس الابتدائية التي تحوي بـرامج لذوي صعوبات تعلم بنات بمدينة الرياض. وفقا لإحصائية وحدة جمع وتحليل البيانات بوزارة التعليم فان عددها كـان (1) مدرسـة. تم ترشيح مدرسـة ابتدائيـة مـن قبـل مكتب التوجيـه بـالوزارة لانطبـاق مواصفات البحث عليها حيث يتوفر بها: برنامج لذوات صعوبات التعلم، توفر بيئة تعلمية مناسبة للطالبات، عدد الطالبات العاديات وذوات صعوبات التعلم يمثل المتوسط الدارج لمدارس منطقة الرياض، مرونة الادارة.

بلغ حجم عينة الدراسة (0 1 ) طالبة من طالبات الصف الرابع الابتدائي موزعين في ثلاث مجموعات هي: ذوات صعوبات التعلم، ذوات الاداء الضعيف، ذوات الاداء المتوسط في مهارات لغتي. تم اختيارهن بعدة طرق: الملاحظة، تحليل وفحص الاعمال، ترشيح معلمة لغتي، تطبيق اختبار من تصميم الباحثة.

طبقت الطرق السابقة على كافة طالبات الصف الرابع. ففي الأسبوع الأول قامت الباحثة بالماحظة لمدة أسبوعين في حصة لغتي للتعرف على: اسلوب تدريس المعلمة، الطالبات ومستوى ادائهن ونوعية المهارات التي يحتجن لها. كما تم تحليل وفحص مهارات التعبير الكتابي المعروضة في كتاب لغتي، والتي أظهرت أن معظم الطالبات لديهن أخطاء متتوعة. ورشحت معلمة الصف بعض الطالبات لتلقي البرنامج. للتأكد من مناسبة المجموعة المختارة للبرنـامج تم الاطـلاع على تحصيل الطالبات في مقرر لغتي الفصل الدراسي الأول وحصـر اسماء الطالبات اللاتي يتلقين خدمات برامج الصعوبات في المدرسة. أخير تم تطبيق اختبار لمهارات التعبير على جميع طالبات الصف (7 ( ك طالبة).

جلدول (1) مستوى مهارات التعبير الكتابي للدى طالبات الصف الرابع

\begin{tabular}{|c|c|c|c|c|c|}
\hline \multicolumn{4}{|c|}{ وصــــــــالاداي } & \multirow{2}{*}{ المهـــــــــــــــارة } & \\
\hline $\bar{y}$ & 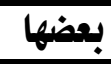 & 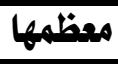 & جميعها & & \\
\hline \multicolumn{4}{|c|}{ تمت لدى جميع الطالبات } & \multirow{2}{*}{ الأفكار الفرة الأساسية تعبر عن الفوعم الفكرة الأساسية } & \multirow{2}{*}{ الموضوى } \\
\hline$\% \varepsilon$ & $\% r$ & $\% V$ & $\% \wedge \wedge$ & & \\
\hline$\%$ \% & $\% 1$. & $\% r$ & $\%$ oV & يوجد ترابط بين الجمل & الشكل \\
\hline$\% \vee$ & $\% \vee$ & $\% \leq$ & $\% \wedge$. & الكلمات مرتبة بطريقة صحيحة داخل الجملة لتعطي معنى & 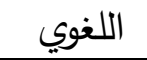 \\
\hline \multicolumn{2}{|c|}{ 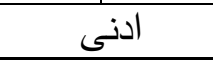 } & \multicolumn{2}{|c|}{ اعلى } & \multicolumn{2}{|l|}{ المهارات } \\
\hline \multicolumn{2}{|c|}{ r } & \multicolumn{2}{|c|}{ 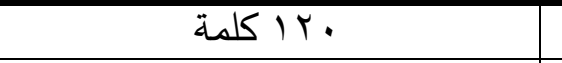 } & \multicolumn{2}{|c|}{ عدد المفردات المستخدمة في النص } \\
\hline \multicolumn{2}{|c|}{$r$} & & \multicolumn{2}{|l|}{ عدد المفردات في الجملّة } \\
\hline \multicolumn{2}{|c|}{1} & & \multicolumn{2}{|l|}{ عدد الجمل في النص } \\
\hline
\end{tabular}


من خلال الاساليب السابقة لوحظ ان جميع طالبات الصف الرابع لديهن مهارة الكتابة عن محتوى الموضوع من فكرة رئيسية وجمل داعمة ومفسرة للفكرة الاساسية إذا اعطي الموضوع لهم بشكل مباشر • فغالبيتهن تمكن من كتابة جمل مساندة تدعم الفكرة الرئيسية لكن نسبة بسيطة كان لديهم صـعوبة في ذلك، جدول ( ) وضـح النسبة المئويـة لمستوى مهارات التعبير الكتابي لدى طالبات الصف الرابع.

امـا بالنسـبة الشكل اللغـوي للكتابـة فقامـت معظم الطالبـات بكتابـة كلمـات مرتبـة بطريقـة

صحيحة داخل الجملة لتعطي معنى، بينما اظهرن انخفاض في القدرة على الربط بين الجمل. عدد المفردات المستخدمة في النص تراوحت مـا بين كلمتين يتم تكرارها الى ( • I ) كلمة، وهذا أثر على عدد الجمل حيث تراوحت ما بين جملة الى (؟؟) جملة لدى البعض، وتراوح عدد الكلمات في الجملة الواحدة ما بين اثتثين الى ثمان. بناء على هذه الخطوات تم ترشيح الطالبات الملتحقات بغرفة المصادر ليمثلن مجموعة ذوات صعوبات التعلم وهن خمس طالبات. كما تم ترشيح خمس طالبات اخريات كطالبات ذوات مستوى الضعيف وخمس من ذوات المستوى المتوسط.

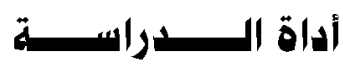
تكونت ادوات الدراسة من قائمة مهارات التعبير الكتابي، واختبار القياس القبلي والبعدي، وبرنامج تدريس مهارات التعبير الكتابي باستخدام استراتيجية KWL. وسيتم شرح وتوضيح كل اداة على حدة.

\section{اولا : قائمة بمهارات التعبير الكتابي متسلسلة}

قبل البدء بتطبيق الدراسة قامت الباحثة ببناء قائمة بمهارات التعبير الكتابي وفق تسلسلها

النمـائي. نتجـت هذه القائمسة عن مسـح موسـع لـأدب التربـوي والبحثي ذو الصـلة بتقيـيم مهارات التعبيـر الكتابي ودرجـة امـتلاك الطلبـة العـاديين لهذه المهارات (عسيري، 9 الـ ب؛ نـور الـدين،

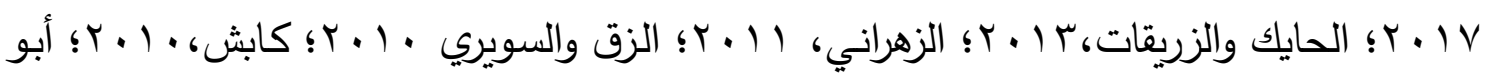

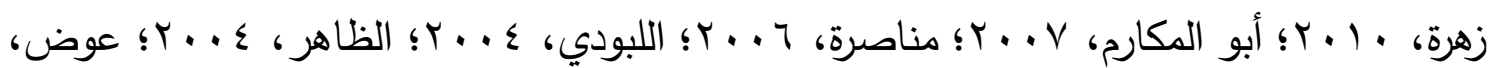
ץ . . ץ؛ فضل الله ،909 (19). إضافة إلى الرجوع إلى مناهج وزارة التعليم للغة العربية والإطار العام 
للمناهج وأدلة المعلمين للمرحلة الابتدائية، كما تم الاستعانة بمعلمات اللغة العربية في المدرسة لتحديد المهارات الاكثر اهمية لطالبات الصف الرابع مع الاخذ بالاعتبار مهارات الحد الادنى التي حددت من قبل الوزارة. تكونت القائمة من 07 مهارة موزعة بين مجالين المحتوى والثكل اللغوي.

\section{ثانيا : اختبار لقياس مهارات التعبير الكتابي (اعداد الباحثة)}

بعد مراجعة الإطار النظري للبحث والدراسات السابقة التي تناولت التعبير الكتابي في اللغة العربية والإنجليزية لاى التلاميذ ذوي صعوبات التعلم، والاطلاع على المقاييس التي تتاولت تقييم التعبير الكتابي في اللغة الإنجليزية لدى التلاميذ، قامت الباحثة بإعداد الاختبار مع مراعاة توفر اساسياته (هدفه، الطريقة، الوقت، التصحيح). كان هدف الاختبار تحديد مستوى مهارات التعبير الكتابي في اللغة العربية لدى طالبات الصف الرابع الابتدائي من ذوات صعوبات التعلم. وتم تحديد طريقة القياس بتقديم اختبار تحريري جماعي للطالبات المشاركات. كان عبارة عن سؤال مقالي واحـد مفتوح عن موضـوع مثير للطالبـة "اكتبـي عن مـاذا تريدين أن تصسبحي او تعملي عندما تكبرين؟" تم تحديد وقت الاختبار بثلاثين دقيقة وهي متوسط الوقت المستغرق للتعبير من خلال ملاحظة الطالبات في الاسبوعين الاوليين وكما ورد في العديد من الدراسات. يصحح وفق معايير محدة مسبقا (جدول () وهي المهارات التي وجدت الباحثة مناسبتها لمستوى الطالبات.

\section{ثالثا : البرنامج التلديبي (اعداد الباحثة)}

تكون البرنامج من (r ( ) اسبوعا موزعة كالتالي: اسبوعين ملاحظة وجمع معلومات، اسبوع تمهيد شمل الاختبار القبلي، وتسع اسابيع تطبيق للبرنامج (דr حصة)، واسبوع اغلاق (اختبار بعدي وحفل ختامي). مدة تنفيذ الدراسـة كانت ثلاثتة أشـهر وبواقع r حصص أسبوعيا، ومدة الحصة (0؛ دقيقة). تم تدريس الطالبات في غرفة المصادر بالمدرسة في حصص اللغة العربية. كانت موضوعات البرنامج من كتاب الطالبة باستخدام استراتيجيات التعلم النشط. قسم البرنامج إلى ثلاثثة مراحل تدريبيـة وفقا لمواضيع مقرر لغتي: الحشرات والطيور، الرياضــة والالعـاب، المهن

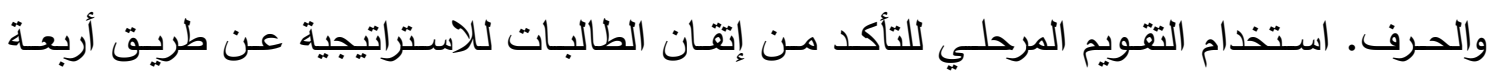


اختبارات تحريرية اثتاء تطبيق الاستراتيجية. لتفعيل الاستراتيجية طُلب من كل تلميذة في بداية كل وحدة تعبئة نموذج الاستراتيجية. وفي نهاية كل حصة تكتب ماذا تعلمت.

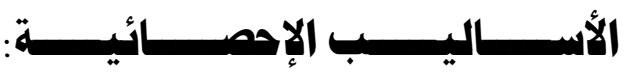

صدق أداة الدراسة

للتحقق من صدق اداة الدراسة (الاختبار) قامت الباحثة بما يلي:

\section{الصلدق الظاهري لأداة اللدراسة (صلق المحكمين) :}

بعد الانتهاء من بناء أداة الدراسة (اختبار التعبير)؛ تم عرضها على عدد (0) من المحكمين،

للحكم على مدى وضوح العبارات وملائكتها لسن ومستوى الصف الرابع الابتدائي ووضـع التعديلات والاقتراحات لتطويرها. قامت الباحثة بإجراء التعديلات اللازمة وفقا لآرائهم حتى أصبحت أداة الدراسـة في صورته شبه النهائية ليدخل مرحلة التحقق من الصدق والثبات، وذلك كما يلي:

\section{صلق الاتساق الداخلي لأداة اللدراسة ( الاختبار) :}

بعد تطبيقها ميدانياً تم حساب معامل الارتباط بيرسون لمعرفة الصدق الداخلي للاختبار ، وتم

حساب معامل الارتباط بين درجة كل عبارة من عبارات أداة الدراسة بالدرجة الكلية للمحور الذي تنتمي إليه العبارة كما يوضح ذلك جدول (Y)، حيث يظهر أن جميع الأبعاد دالة عند مستوى (1 •, )، حيث

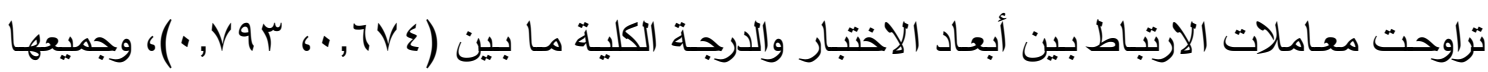
معاملات ارتباط جيدة، وهذا يعطي دلالـة على ارتفاع معـاملات الاتسـاق الداخلي، كمـا يثـير إلى مؤشرات صدق مرتفعة وكافية يمكن الوثوق بها في تطبيق أداة الدراسة الحالية (الاختبار). جدول رقم (ץ) معاملات ارتباط بيرسوز لأبعاد التعبير الكتابي بالدرجة الكلية للاختبار

\begin{tabular}{|c|c|}
\hline معـــامــل الارتبــــاط & الأبعــــــــــاد \\
\hline$* *, \vee \wedge \wedge q$ & حصيلة المفردات \\
\hline$* *, 7 \vee \varepsilon$ & عدد المفردات في الجملة \\
\hline$* *, \vee \vee q r$ & عدد الجمل في النص \\
\hline
\end{tabular}

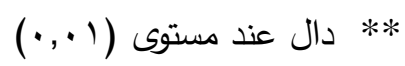


لقياس مدى ثبات أداة الدراسة (الاختبار) استخدمت الباحثة إعادة الاختبار ، وذلك كما يلي:

جلول رقم (ץ) معاملات الارتباط للتطبيقين الأول والثاني للاختبار

\begin{tabular}{|c|c|c|}
\hline معـــامـــل الثبــــات & الأبعــــــــــــاد & 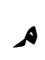 \\
\hline$\cdot, \vee \cdot \Lambda$ & حصيلة المفردات & 1 \\
\hline$\cdot, \vee>17$ & عدد المفردات في الجملة & r \\
\hline$\cdot, V Y O$ & عدد الجمل في النص & r \\
\hline$\cdot, V T Y$ & الارجة & \\
\hline
\end{tabular}

يوضـح الجدول رقم (r) أن أداة الدراسـة (الاختبار) يتمتع بثبات مقبول إحصـائياً، حيث

بلغت قيمـة معامل الارتباط بين الدرجة الكلية للاختبار ( VTY, • ) وهي درجة ارتباط عالية، كما

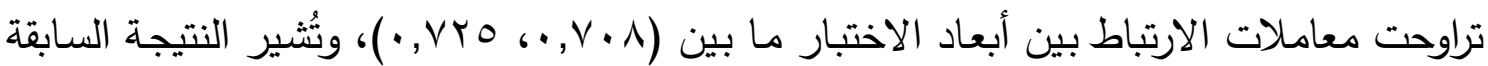
إلى أن الاختبار يتمتع بدرجة ثبات جيدة يمكن الوثوق بها في تطبيق أداة الدراسة الحالية.

\section{الأساليب الإهصائية المسُستخدهة في اللدراسة:}

لتحقيق أهداف الدراسة تم استخدام العديد من الأساليب الإحصائية المناسبة باستخدام الحزم الإحصائية للعلوم الاجتماعية (SPSS) Statistical Package for Social Sciences (SP) وفيما

يلي عرض الأساليب الإحصائية المستخدمة: معامـل ارتبـاط بيرسـون (Pearson correlation) لحســاب صــدق الاتســاق

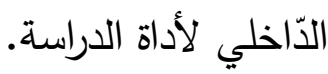

إعادة الاختبار (Re-Test)، لحساب معامل ثبات المحاور المختلفة لأداة الدراسة. اختبار ويلكوكسون (Wilcoxon) للتعرف على الفروق بين التطبيقين القبلي والبعدي التلاميذ على اختبار التعبير الكتابي. اختبار مان ويتني (Mann-Whitney) للتعرف على الفروق بين متوسط درجات طالبات صعوبات التعلم وأقرانهن العاديين في التعبير الكتابي. مربع إيتا (Eta Square) للتعرف على أثر استخدام استراتيجية KWL في تدريس التعبير الكتابي لطالبات صعوبات التعلم واقرانهم العاديين. 
السؤال الاول: هل توجد فروق ذات دلالة احصـائية بين درجـات القيـاس القبلي والبعـدي بين

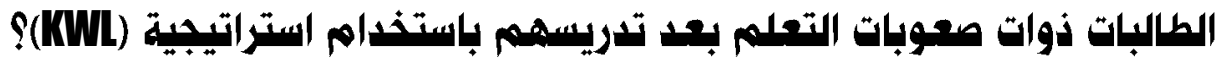

للإجابـة على هذا السؤال، تـم اسـتخدام اختبـار ويلكوكسون (Wilcoxon)، وذلك كمـا

$$
\text { يتضح من خلال الجدول رقم (ع). }
$$

جلول رقم (؟) المتوسطات الحسابية والانحراف المعياري للدرجات تلميذات صعوبات التعلم بالتطبيقين القبلي والبعدي على اختبار التعبير الكتابي

\begin{tabular}{|c|c|c|c|c|}
\hline الانحراف المعياري & المتوسط الحسابي & العدد & التطبيق & الأبعـــــــاد \\
\hline$\cdot, \wedge \varepsilon$ & $\Lambda, r$. & 0 & القبلي & \multirow{2}{*}{ حصيلة المفردات } \\
\hline$q, \cdot r$ & $r q, r$. & 0 & البعدي & \\
\hline$\cdot, 91$ & r, rᄉ & 0 & القبلي & \multirow{2}{*}{ عدد المفردات في الجملة } \\
\hline $1, r$. & $\varepsilon, \wedge$. & 0 & البعدي & \\
\hline $1,7 \varepsilon$ & $r, r$. & 0 & القبلي & \multirow{2}{*}{ عدد الجمل في النص } \\
\hline $0, \varepsilon$. & $9, \wedge$. & 0 & البعدي & \\
\hline$T, \cdot T$ & $1 \leq, V \wedge$ & 0 & القبلي & \multirow{2}{*}{ الدرجة الكلية لاختبار } \\
\hline $1 \pi, 00$ & $\varepsilon r, \wedge$. & 0 & البعدي & \\
\hline
\end{tabular}

يتضح من الجدولين رقم (ع، 0) أن هناك فروقاً ذات دلالة إحصائية عند مستوى (0., • )

بين متوسط رتب طالبات صعوبات التعلم بالتطبيقين القبلي والعبدي بالدرجة الكلية لاختبار التعبير الكتابي وأبعاده الفرعية المتمثلة في (حصيلة المفردات - عدد الجمل في النص)، وذلك لصـالح

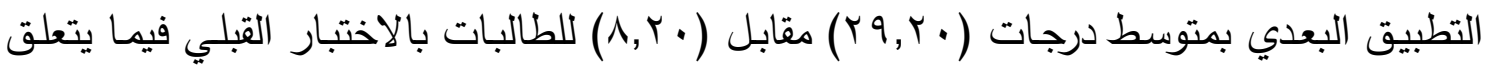

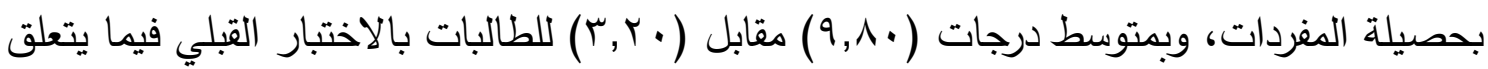

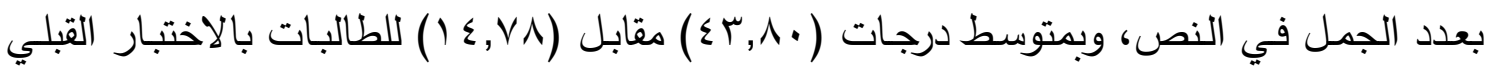
فيمـا يتعلق بالدرجـة الكليـة لاختبـار التعبيـر الكتابي، وتُشير النتيجـة السـابقة إلى أن هنـالك أثر لاستخدام استراتيجية KWL في تدريس التعبير الكتابي لطالبات صعوبات التعلم. وأوضـحت النتائج أنـه لا توجد هنـاك فروقـاً ذات دلالمة إحصـائية بين متوسط رتب طالبـات صعوبات التعلم بالتطبيقين القبلي والبعدي فيما يتعلق بعدد المفردات في الجملـة، حيث بلغت قيمـة 
مستوى الدلالة (ع V • . •)، وهي قيمة أكبر من (0 . . •) أي غير دالة إحصائياً، وتُشير النتيجة السابقة إلى تقارب مستويات التلاميذ بالتطبيقين القبلي والبعدي فيما يتعلق بعدد المفردات في الجملة. جلدول رقم (0) نتائج اختبارويلكوكسون (Wilcoxon) للتعرف على الفروق ذات الدلالة الإحصائية بين رتب درجات طالبات صعوبات التعلم على اختبار التعبير الكتابي بالتطبيقين القبلي والبعدي

\begin{tabular}{|c|c|c|c|c|c|c|c|}
\hline مربع إيتا & مستوى اللالة & قيمة (Z) & مجموع الرتب & متوسط الرتب & العلد & \multicolumn{2}{|c|}{ الأبعاد } \\
\hline \multirow{4}{*}{$\cdot, V \vee$} & \multirow{4}{*}{$\cdot, \cdot \leq r$} & \multirow{4}{*}{$r, \cdot r r$} & $\cdot, \cdot$ & $\cdot, \cdot$ & . & الرتب السالبة & \multirow{4}{*}{ المفردات حصيلة } \\
\hline & & & 10, & $r, \cdot$ & 0 & الرتبة الموجبة & \\
\hline & & & & & $\cdot$ & الرتعادلة & \\
\hline & & & & & 0 & الإجمالي & \\
\hline \multirow{4}{*}{ سז, • } & \multirow{4}{*}{$\cdot, \cdot \vee \leqslant$} & \multirow{4}{*}{$1, \vee \wedge \neg$} & 1 & 1 & 1 & الرتب السالبة & \multirow{4}{*}{ في الجملة المفردات } \\
\hline & & & $1 \leqslant$, & $r, 0$. & $\varepsilon$ & الرتبة الموجبة & \\
\hline & & & & & $\cdot$ & الرتعادلة & \\
\hline & & & & & 0 & الإجمالي & \\
\hline \multirow{4}{*}{$\cdot, \leqslant 7$} & \multirow{4}{*}{$\cdot, \cdot \leq r$} & \multirow{4}{*}{$r, \cdot r r$} & $\cdot, \cdot$ & $\cdot, \cdot$ & . & الرتب السالبة & \multirow{4}{*}{ عدد الجمل في } \\
\hline & & & 10, & $r, \cdot$ & 0 & الرتبة الموجبة & \\
\hline & & & & & - & المتعادلة & \\
\hline & & & & & 0 & الإجمالي & \\
\hline \multirow{4}{*}{$\cdot, \mathrm{VO}$} & \multirow{4}{*}{$\cdot, \sum Y$} & \multirow{4}{*}{$r, \cdot r r$} & $\cdot, \cdot$ & $\cdot, \cdot$ & . & الرتب السالبة & \multirow{4}{*}{ لاختبار التعبير الكتية } \\
\hline & & & 10, & $r$, , & 0 & الرتبة الموجبة & \\
\hline & & & & & - & الرتعادلة & \\
\hline & & & & & 0 & الإجمالي & \\
\hline
\end{tabular}

وبينت النتائج بالجدول رقم (0) أن قيمة مربع إيتا لنتائج التطبيقين القبلي والبعدي فيما يتعلق بحصيلة المفردات بلغت (VV, • )، وفيما يتعلق بعدد الجمل في النص (T ( ؛, •)، وبالنسبة للدرجة الكلية لاختبار التعبير الكتابي (V0, • )، ونلاحظ أنها تجاوزت القيمة الدالتة على الأهمية التربويـة للنتائج الإحصـائية في البحوث النفسية والتربويـة ومقدارها (ع ا . • (مراد، . . . ب )، وهذا التباين بين متوسطي درجـات الطالبـات بـالتطبيقين القبلي والبعدي يرجـع إلى متغير المعالجـة 
السلوكية وهو استخدام استراتيجية KWL ؛ أي أن هناك أثر لاستخدام استراتيجية KWL في تدريس التعبير الكتابي لطالبات صعوبات التعلم.

وقد اتفقت نتيجة الدراسة الحالية مع نتيجة عدد من الدارسات التي استخدم الباحثين فيها

استراتيجيات متتوعـة لتدريس التعبيـر الكتابي للتلاميذ ذوي صسوبات التعلم كدراسـة: انثاصسي

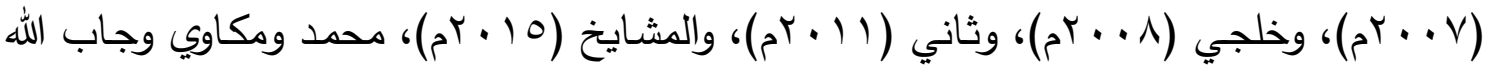
(V) تتميـة مهارة التعبير الكتابي. ضـرورة تدريس المهارات فوق المعرفيـة للتلاميذ الذين يعـانون مـن صعوبات التعلم بشكل عام.

السؤال الثاني: هل توجد فروق ذات دلالة احصائية بين درجات القياس القبلي والبحدي بـين

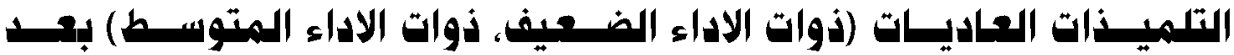

\section{تدريسهم باستخدام استراتهية (KWL)}

للإجابة هذا السؤال تم استخدام اختبار ويلكوكسون (Wilcoxon)، تم فحص أداء التلميذات

ذوات الأداء الضعيف أولا، وذلك كما يتضح من خلال الجدول رقم (7)، وذلك على النحو التالي: جلول رقم (7) المتوسطات الحسابية والانحراف المعياري للدرجات الطالبات الضعيفات بالتطبيقين القبلي والبعدي على اختبار التعبير الكتابي

\begin{tabular}{|c|c|c|c|c|}
\hline الانحراف المعياري & المتوسط الحسابي & العلد & التطبيق & الأبعاد \\
\hline $1, r$. & $11, r$. & 0 & القبلي & \multirow{2}{*}{ حصيلة المفردات } \\
\hline$r Y, 11$ & $\varepsilon 0, r$. & 0 & البعدي & \\
\hline 1,04 & $r, T$. & 0 & القبلي & \multirow{2}{*}{ عدد المفردات في } \\
\hline $1,(1)$ & $\varepsilon, 90$ & 0 & البعدي & \\
\hline $1,0 Y$ & r, ¿. & 0 & القبلي & \multirow{2}{*}{ عدد الجمل في } \\
\hline$r, 97$ & $1 \cdot, \wedge$. & 0 & البعدي & \\
\hline$r, v \wedge$ & $17, r$. & 0 & القبلي & \multirow{2}{*}{ لاختبار التعبير الارجة الكلية } \\
\hline$r ૫, \vee \wedge$ & $7 ., 90$ & 0 & البعدي & \\
\hline
\end{tabular}

يتضح من خلال الجدولين رقم (T ، V) أن هنالك فروقاً ذات دلالة إحصـائية عند مستوى (0 • , • ) بين متوسط رتب الطالبات الضعيفات بالتطبيقين القبلي والعبدي بالدرجة الكلية لاختبار 
التعبير الكتابي وأبعاده الفرعية، وذلك لصـالح التطبيق البعدي بمتوسط درجات ( • ؟ ؛ ) مقابل ( • ( I, ) للطالبات بالاختبار القبلي فيما يتعلق بحصيلة المفردات، وبمتوسط درجات (90,ع مقابل ( • r, (Y) للطالبات بالاختبار القبلي فيما يتعلق بعد المفردات في الجملة، وبمتوسط درجات

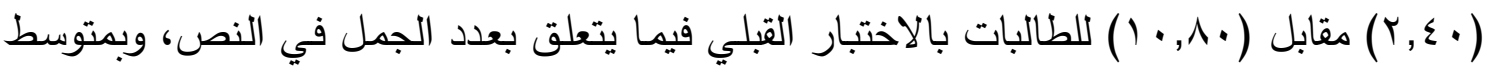

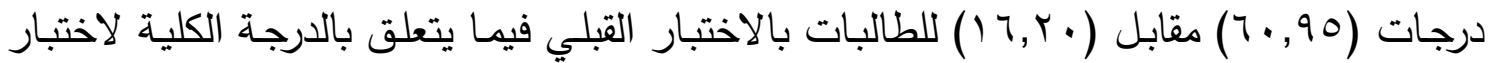
التعبير الكتابي، وتُشير النتيجة السابقة إلى أن هناك أثر لاستخدام استراتيجية KWL في تدريس التعبير الكتابي للطالبات الضعيفات.

جلدول رقه (V) نتائج اختبارويلكوكسون (Wilcoxon) للتعرف على الفروق ذات الدلالة الإحصائية بين رتب درجات الطالبات الضعيفات على اختبار التعبير الكتابي بالتطبيقين القبلي والبعدي

\begin{tabular}{|c|c|c|c|c|c|c|c|}
\hline مربع إيتا & مستوى الدلالة & قيمة (Z) & مجموع الرتب & متوسط الرتب & العدد & عــاد & الأبع \\
\hline \multirow{4}{*}{$\cdot, 7$. } & \multirow{4}{*}{$\cdot, \cdot \leq r$} & \multirow{4}{*}{$T, \cdot Y r$} & $\cdot, \cdot$ & $\cdot, \cdot$ & . & الرتب السالبة & \multirow{4}{*}{ المفردات } \\
\hline & & & 10, & $r$, & 0 & الرتبة الموجبة & \\
\hline & & & & & . & الرتب المتعادلة & \\
\hline & & & & & 0 & الإجمالي & \\
\hline \multirow{4}{*}{$\cdot, r q$} & \multirow{4}{*}{$\cdot, \cdot \varepsilon r$} & \multirow{4}{*}{$r, \cdot Y r$} & $\cdot, \cdot$ & $\cdot, \cdot$ & . & الرتب السالبة & \multirow{4}{*}{ | عدي الجمبلة } \\
\hline & & & 10, & $r, \cdot$ & 0 & الرتبة الموجبة & \\
\hline & & & & & . & الرتب المتعادلة & \\
\hline & & & & & 0 & الإجمالي & \\
\hline \multirow{4}{*}{$\cdot, v_{1}$} & \multirow{4}{*}{$\cdot, \cdot \leq Y$} & \multirow{4}{*}{$r, \cdot r r$} & $\cdot, \cdot$ & $\cdot, \cdot$ & . & الرتب السالبة & \multirow{4}{*}{ عدد الجمل في } \\
\hline & & & 10, & $r$, & 0 & الرتبة الموجبة & \\
\hline & & & & & . & الرتب المتعادلة & \\
\hline & & & & & 0 & الإجمالي & \\
\hline \multirow{4}{*}{$\cdot, 70$} & \multirow{4}{*}{$\cdot, \cdot \leq r$} & \multirow{4}{*}{$T, \cdot T r$} & $\cdot, \cdot$ & $\cdot, \cdot$ & . & الرتب السالبة & \multirow{4}{*}{ التاختبار الكبير الكتابية } \\
\hline & & & 10, & $r$, & 0 & الرتبة الموجبة & \\
\hline & & & & & . & الرتب المتعادلة & \\
\hline & & & & & 0 & الإجمالي & \\
\hline
\end{tabular}

وبينت النتائج بالجدول رقم V) أن قيمة مربع إيتا لنتائج التطبيقين القبلي والبعدي فيما يتعلق بحصيلة المفردات بلغت ( • ج, •)، وفيما يتعلق بعدد المفردات في الجملة (وب, •)، وفيما 
يتعلق بعدد الجمل في النص (V), • ))، وبالنسبة للدرجة الكلية لاختبار التعبير الكتابي (0T, •)، ونلاحظ أنها تجاوزت (ع ( • ))، وهذا التباين بين متوسطي درجات الطالبات بـالتطبيقين القبلي والبعدي يرجع إلى متغير المعالجة السلوكية وهو استخدام استراتيجية KWL؛ أي أن هناك أثر لاستخدام استراتيجية KWL في تدريس التعبير الكتابي للطالبات الضعيفات. الطالبات ذوات الاداء المتوسط. تم استخدام اختبار ويلكوكسون (Wilcoxon) للتعرف على إذا مـا كانـت هنـالك فروقاً ذات دلالـة إحصـائية بـين درجات الطالبـات متوسطي التحصـيل بالتطبيقين القبلي والبعدي باختبار التعبير الكتابي، ويتضـح ذلك من خلال الجدول رقم (^، 9). يتضـح من خلال هاذين الجدولين أن هناك فروقاً ذات دلالة إحصـائية عند مستوى (0. . •) بين متوسط رتب الطالبات متوسطي التحصيل بالتطبيقين القبلي والعبدي بالدرجة الكلية لاختبار التعبير الكتابي وأبعاده الفرعية المتمثلة في (حصيلة المفردات - عدد الجمل في النص)، وذلك لصـالح

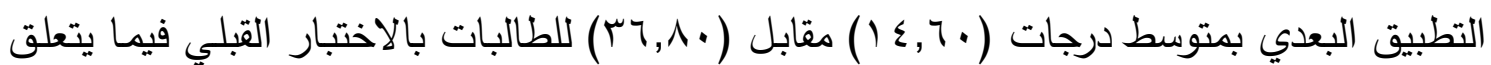
بحصيلة المفردات، وبمتوسط درجات ( • عـ) مقابل ( • , q) للطالبات بالاختبار القبلي فيما يتعلق بعدد الجمل في النص، وبمتوسط درجات (ع •,بr) مقابل ( • ع, • •) للطالبات بالاختبار القبلي فيمـا يتعلق بالدرجـة الكليـة لاختبـار التعبيـر الكتابي، وتُشـير النتيجـة السـابقة إلى أن هنـاك أثر لاستخدام استراتيجية KWL في تدريس التعبير الكتابي للطالبات متوسطي التحصيل. جلول رقم ( ) المتوسطات الحسابية والانحراف المعياري للدرجات الطالبات متوسطي التحصيل بالتطبيقيز القبلي والبعدي على اختبار التعبير الكتابي

\begin{tabular}{|c|c|c|c|c|}
\hline الانحراف المعياري & المتوسط الحسابي & العلد & التطبيق & الأبعـــــاد \\
\hline $1,7 V$ & $1 \varepsilon, 7$. & 0 & القبلي & \multirow{2}{*}{ حصيلة المفردات } \\
\hline$I V, \leqslant 7$ & 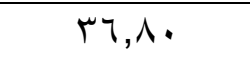 & 0 & البعدي & \\
\hline $1,\{1$ & $\varepsilon, \varepsilon \varepsilon$ & 0 & القبلي & \multirow{2}{*}{ عدد المفردات في } \\
\hline., 00 & $\varepsilon, \varepsilon$. & 0 & البعدي & \\
\hline $1, \cdots$ & $\varepsilon, \ldots$ & 0 & القبلي & \multirow{2}{*}{ عدد الجمل في } \\
\hline$T, Y V$ & $9, r$. & 0 & البعدي & \\
\hline$r, \cdot \varepsilon$ & $T r, \cdot \Sigma$ & 0 & القبلي & \multirow{2}{*}{ لاختبار التعبير الكتية } \\
\hline$Y \cdot, 97$ & $0 ., \varepsilon$. & 0 & البعدى & \\
\hline
\end{tabular}


في حين أوضحت النتائج أنه لا توجد هناك فروقاً ذات دلالة إحصائية بين متوسط رتب الطالبات متوسطي التحصيل بالتطبيقين القبلي والبعدي فيما يتعلق بعد المفردات في الجملة، حيث بلغت قيمة مستوى الدلالة (199, •))، وهي قيمة أكبر من (0. •. •) أي غير دالة إحصائياً، حيث

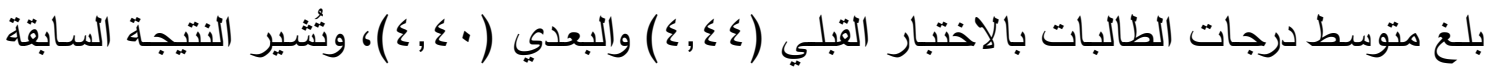
إلى تقارب مستويات التلاميذ بالتطبيقين القبلي والبعدي فيما يتعلق بعدد المفردات في الجملة. جلول رقه (9) نتائج اختبارويلكوكسون (Wilcoxon) للتعرف على الفروق ذات الدلالة الإحصائية بين رتب لتب درجات الطالبات متوسطي التحصيل على اختبار التعبير الكتابي بالتطبيقين القبلي والبعدي

\begin{tabular}{|c|c|c|c|c|c|c|c|}
\hline مربح إيتا & مستوى & قيمة (Z) & مجموع الرتب & متوسط & العلد & 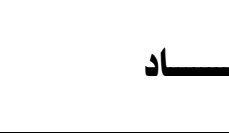 & الأبع \\
\hline \multirow{4}{*}{$\cdot, 0$} & \multirow{4}{*}{$\cdot, \cdot \leq r$} & \multirow{4}{*}{$r, \cdot r r$} & $\cdot, \cdot$ & $\cdot, \cdot$ & · & الرتب السالبة & \multirow{4}{*}{ حصيلة المفردات } \\
\hline & & & 10, & $r$, & 0 & الرتبة الموجبة & \\
\hline & & & & & - & الرتب المتعادلة & \\
\hline & & & & & 0 & الإجمالي & \\
\hline \multirow{4}{*}{$\cdot, \cdot$} & \multirow{4}{*}{$\cdot, \wedge 9 r$} & \multirow{4}{*}{ • } & $\wedge, \cdot$ & $Y, T V$ & r & الرتب السالبة & \multirow{4}{*}{ عدد المفردات في } \\
\hline & & & $\mathrm{V}$, & $r, 0$. & $r$ & الرتبة الموجبة & \\
\hline & & & & & - & الرتب المتعادلة & \\
\hline & & & & & 0 & الإجمالي & \\
\hline \multirow{4}{*}{$\cdot, 09$} & \multirow{4}{*}{$\cdot, \cdot \varepsilon r$} & \multirow{4}{*}{$r, \cdot r r$} & $\cdot, \cdot$ & $\cdot, \cdot$ & - & الرتب السالبة & \multirow{4}{*}{ عدد الجمل في } \\
\hline & & & 10, & $r, \cdot$ & 0 & الرتبة الموجبة & \\
\hline & & & & & - & الرتب المتعادلة & \\
\hline & & & & & 0 & الإجمالي & \\
\hline \multirow{4}{*}{$\cdot, 09$} & \multirow{4}{*}{$\cdot, \cdot \leq r$} & \multirow{4}{*}{$r, \cdot Y r$} & $\cdot, \cdot$ & $\cdot, \cdot$ & . & الرتب السالبة & \multirow{4}{*}{ لاختبار التعبير الارجة الكلية } \\
\hline & & & 10, & $r, \cdot$ & 0 & الرتبة الموجبة & \\
\hline & & & & & - & الرتب المتعادلة & \\
\hline & & & & & 0 & الإجمالي & \\
\hline
\end{tabular}

وبينت النتائج بالجدول رقم (9) أن قيمة مربع إيتا لنتائج التطبيقين القبلي والبعدي فيما يتعلق بحصيلة المفردات بلغت (•.0, •)، وفيما يتعلق بعدد الجمل في النص (09, •)، وبالنسبة للدرجة الكلية لاختبار التعبير الكتابي (ه, • )، ونلاحظ أنها تجاوزت (ع ( , )، وهذا التباين بين 
متوسطي درجات الطالبات بالتطبيقين القبلي والبعدي يرجع إلى متغير المعالجة السلوكية وهو

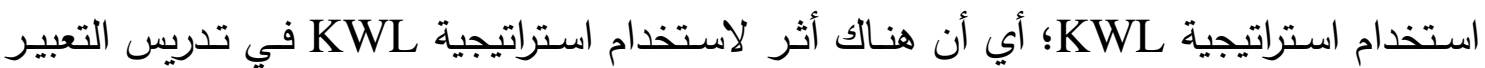
الكتابي للطالبات متوسطي التحصيل.

السؤال الثالث: هـل توجد فروق ذات دلالـة احصـائية بيلن درجات القيساس البعدي بين المجموعات الثلاث؟

للتعرف على إذا ما كانت هناك فروقاً ذات دلالة إحصائية بين درجات التطبيق البعدي لتلميذات صعوبات التعلم وأقراهن العاديين في اختبار التعبير الكتابي، تم استخدام اختبار مان

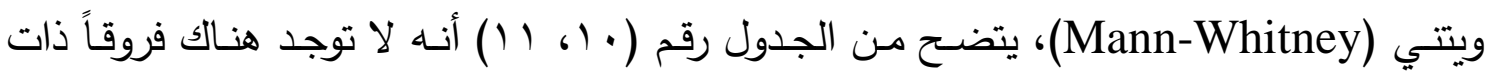
دلالة إحصـائية بين متوسطات رتب طالبات صعوبات التعلم والعاديين (منخفضي التحصيل متوسطي التحصيل) في الارجة الكلية لاختبار التعبير الكتابي وأبعاده، حيث بلغت قيمة مستوى ملئ

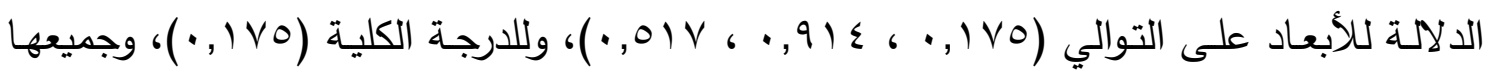
قيم أكبر من (0. . •) أي غير دالة إحصائياً، وتُشير النتيجة السابقة إلى تقارب مستويات طالبات صعوبات التعلم وأقرانهن العاديات بالتطبيق البعدي لاختبار التعبير الكتابي. وعلى الرغم من عدم وجود فروق ذات دلالة إحصائية في التطبيق البعدي بين طالبات صـوبات التعلم وأقرانهن العاديات، إلا أن الدرجـة الكليـة لاختبار التعليم الكتابي كانت لصـالح

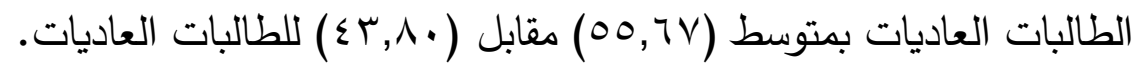
جدول رقه (•) المتوسطات الحسابية والانحراف المعياري للدرجات التطبيق البعدي

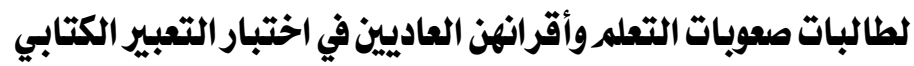

\begin{tabular}{|c|c|c|c|c|}
\hline الانحراف المعياري & المتوسط الحسابي & العــلدد & الطــالبـــات & الأبعــــــاد \\
\hline $9, \cdot \varepsilon$ & $r q, r$. & 0 & صعوبات تعلم & \multirow{2}{*}{ حصيلة المفردات } \\
\hline IT, & $\varepsilon 1, \ldots$ & 0 & عاديين & \\
\hline $1, r$. & $\varepsilon, \wedge$. & 0 & صعوبات تعلم & \multirow{2}{*}{ عدد المفردات في } \\
\hline $1, \cdot \varepsilon$ & $\varepsilon, 7 V$ & 0 & عاديين & \\
\hline $0, \Sigma$. & $q, \wedge$. & 0 & صعوبات تعلم & \multirow{2}{*}{ عدد الجمل في النص } \\
\hline$r, \leqslant 0$ & $1, \ldots$ & 0 & عاديين & \\
\hline $1 \pi, 00$ & $\varepsilon r, \wedge$. & 0 & صعوبات تعلم & \multirow{2}{*}{ الارجة الكلية لاختبار } \\
\hline $17, \mathrm{rV}$ & $00,7 \mathrm{~V}$ & 0 & عاديين & \\
\hline
\end{tabular}


جلدول رقم ( (11) نتائج اختبار مان ويتني (Mann-Whitney) للتعرف على الفروق ذات الدلالة الإحصائية بين درجات التطبيق البعدي لطالبات صعوبات التعلم وأقرانهن العاديات في اختبار التعبير الكتابي

\begin{tabular}{|c|c|c|c|c|c|c|c|}
\hline مستوى الدلالة & قيمة (Z) & قيمة (U) & مجموع الرتب & متوسط الرتب & العـلدد & الطـالبـات & الأبعـــــــــاد \\
\hline \multirow{2}{*}{$\cdot, 1 \vee 0$} & \multirow{2}{*}{$1, r \circ \wedge$} & \multirow{2}{*}{7,} & $r_{1}, \ldots$ & $\varepsilon, r$ & 0 & صعوبات تعلم & \multirow{2}{*}{ حصيلة المفردات } \\
\hline & & & $r \varepsilon, \ldots$ & $\neg, \wedge$ & 0 & عاديين & \\
\hline \multirow{2}{*}{$\cdot, 91 \leq$} & \multirow{2}{*}{$\cdot, 1 \cdot 1$} & \multirow{2}{*}{ Ir,. } & $r V, \ldots$ & $0, \varepsilon$ & 0 & صعوبات تعلم & \multirow{2}{*}{ عدد المغردات في } \\
\hline & & & $r \wedge, \cdots$ & 0,7 & 0 & عاديين & \\
\hline \multirow{2}{*}{$\cdot .01 \mathrm{~V}$} & \multirow{2}{*}{$\cdot, 7 \leqslant 9$} & \multirow{2}{*}{9,0 . } & $r \leq, 0$. & $\varepsilon, 9$ & 0 & صعوبات تعلم & \multirow{2}{*}{ عدد الجمل في النص } \\
\hline & & & $r \cdot, 0$. & $7,1$. & 0 & عاديين & \\
\hline \multirow{2}{*}{$\cdot, 1 \vee 0$} & \multirow{2}{*}{$1, r \circ \Lambda$} & \multirow{2}{*}{$7, \cdot$} & $r_{1}, \ldots$ & $\varepsilon, r$. & 0 & صعوبات تعلم & \multirow{2}{*}{ الارجة الكلية لاختبار } \\
\hline & & & $r \varepsilon, \ldots$ & $\uparrow, \wedge$ & 0 & عاديين & \\
\hline
\end{tabular}

وقد اختلفت نتيجة الدراسـة الحالية مـع نتيجة دراسـة علي (9 . . بم) والتي توصلت إلى

وجود فروق ذات دلالة إحصائية بين ذوي صسوبات التعلم والعاديين في مهارات التعبير الكتابي لدى ذوي صسوبات التعلم والعاديين والمتفوقين من تلاميذ المرحلتين الابتدائية والاعدادية بمملكة البحرين، وذلك لصالح العاديين. بشكل عام اتفقت نتائج الدراسة مع بعض الدراسات السابقة في أن الكثير من التلاميذ ذوي صسوبات التعلم أو الذين لا يعـانون من صسعوبات تعلم يواجهون مشكلات في التعبير الكتابي

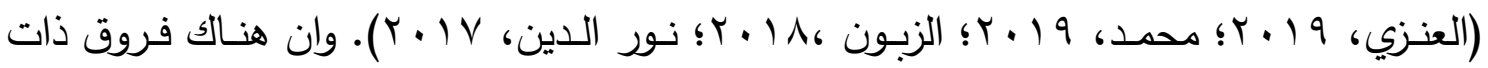
دلالة إحصـائية بين متوسطي رتب درجات القياسين القبلي والبعدي على اختبار التعبير الكتابي لدى المجموعـات الثلاث لصـالح القياس البعدي، وهذه النتيجـة تتفق مـع دراسـة علي (9 . . ؟ )

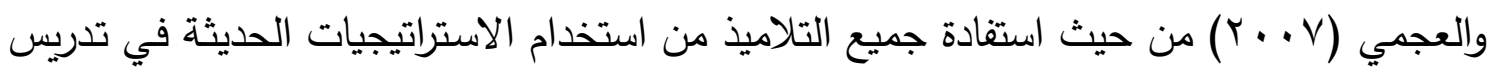
التعبير الكتابي. أكثر مجموعة استجابت للتدخلات هي مجموعة الطالبات الضعيفات يليها ذوات الاداء المتوسط ومن ثم ذوات صعوبات التعلم. ويعزى هذا التحسن إلى اعتماد البرنامج القائم على استخدام استراتيجية KWL على التتوع في الأنشطة وألا تكون على وتيرة واحدة، واستخدم الباحثة 
العديد من الاستراتيجيات والفنيات مثل: النمذجة وطرح الاسئلة، العصف الذهني، العمل الجماعي. ودعمت الأنشطة المستخدمة بالتعزيز الإيجابي لان جميع التلاميذ يحتاجون إلى الثعور بالإنجاز والنجاح وخاصة ذوي صعوبات التعلم.

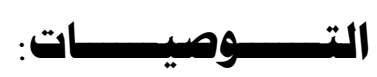

في ضوء النتائج التي تم التوصل إليها تقدم الباحثة بعض التوصيات منها: ضرورة تفهم معلمـات الفصـول العاديـة أهميـة استخدام الاستراتيجيات التربويـة الملائمـة، وتشــيع التعـاون بين التلاميذ، وتقديم تغذية راجعة فورية للنصوص المكتوبة، والعمل على تأسيس روتين للكتابة اليومية، بالإضافة إلى تقديم تعليمات وإرشادات بشكل واضح للتأكد أنهن فهمن المطلوب، والعمل على تتمية مهارات التعبير وفق تسلسها النمائي، مع الحرص على تحسين توجهات الطالبات بشكل عام عن الكتابة. من جهة أخرى تأمل من وزارة التعليم تزويد المرحلة الابتدائية بمنهج منفصل للتعبير قائم على تحليل المهمة وفقاً لتدرج المهارات. أما على المستوى البحثي فينصح بأجراء دراسات للكثف رونف عن الأخطاء اللغوية في التعبير الكتابي لاى الطلبة ذوي صعوبات التعلم في جميع المراحل. 
أبو زهرة، محمد. (· ( + ( ). برنامج قائم على بعض استراتيجيات ما وراء المعرفة " النمذجة لعلاج أخطاء الكتابة لدى تلاميذ الحلقة الإعدادية. دراسات في المناهج وطرق التدريس، 70 (،

ابو زيد، لميا. (9 ( • ؟). فاعلية استخدام استراتيجية (W.K.L) في تدريس مقرر طرق التدريس على تتمية التحصيل المعرفي لاى الطالبات المعلمات بجامعة القصيم وتحسين اتجاهاتهن

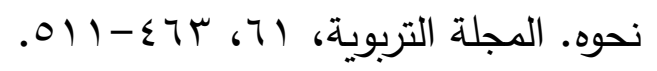
أبونيان، إبراهيم سعد (10 • ؟). صعوبات التعلم طرق التدريس، والاستراتيجيات المعرفية. الرياض: الناشر الدولي.

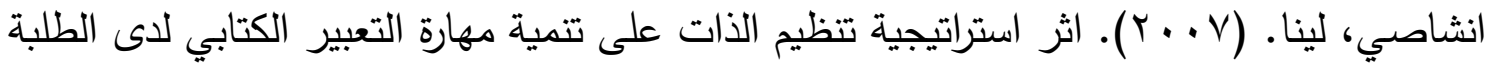
ذوي صعوبات التعلم (رسالة دكتوراة غير منشورة). الجامعة الاردنية، عمان. البتال، زيد. (r ( • ץ). مشكلات الواجب المنزلي لدى التلاميذ ذوي صعوبات التعلم وأقرانهم التلاميذ العاديين في المرحلة الإبتدائية. رسالة التربية وعلم النفس -السعودية، بع، ـr-OV.

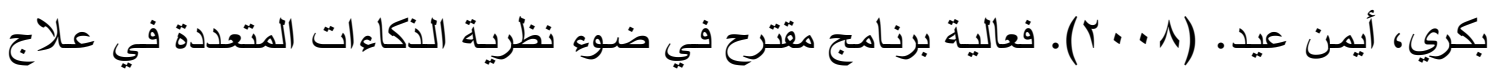
صعوبات التعبير الكتابي لاى تلاميذ الصف الثاني الإعدادي (رسالة دكتوراه). كلية البنات للآداب والعلوم التربوية، جامعة عين شمس. ثاني، نور (1) (1) ـ). فاعلية تدريس الاستراتيجية مقابل التدريس المباشر في تتمية مهارات التعبير الكتابي لذوي صسوبات التعلم من تلميذات المرحلة الابتدائية في دولـة الكويت (رسالة ماجستير غير منشورة). جامعة الخليج العربي، البحرين.

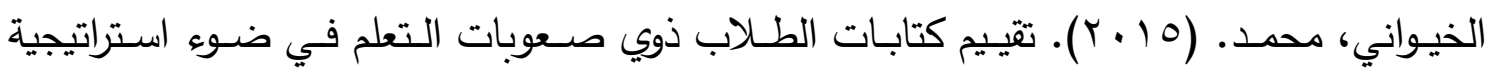
التدوين المزدوج. مجلة كلية التربية جامعة طنطا، ـ7، مب079.07. 


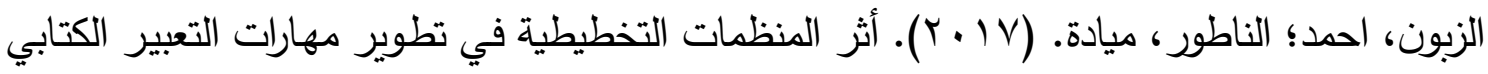

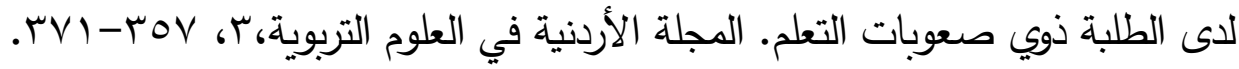

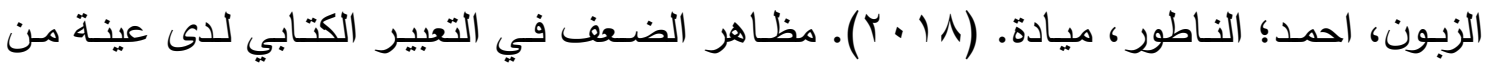

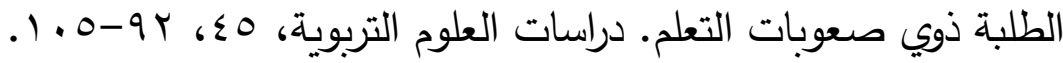
الزق، أحمد؛ السويري، عبدالعزيز .(• ( ؟). المشكلات المتعلقة باللغة الاستقبالية واللغة التعبيرية للطلبة ذوي صعوبات التعلم اللغوية في مدينة الرياض. المجلة الأردنية في العلوم التربوية،

$$
.0 Y-\varepsilon) \text { (1 }
$$

الزهراني، فيصل. (1) ( ب). مدى شيوع صعوبات التعبير الكتابي وعلاقتها بمتغير الصف لدى تلاميذ المرحلة الابتدائية بمحافظة جدة بالمملكة العربية السعودية (رسالة ماجستير غير

$$
\text { منشورة). جامعة الخليج العربي، البحرين. }
$$

عبد العظيم، عبد العظيم صبري. (Y Y (Y). فاعلية برنامج قائم على تعليم اللغة العربية لأغراض خاصـة في تتمية بعض مهارات التعبير الكتابي لدى أطفال المدارس الصديقة بجمهورية

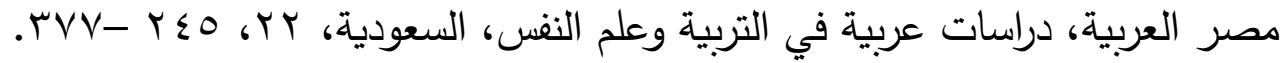
عبد الجواد، احمد. (9 . . ب) مستوى مهارات التعبير الكتابي لدى الطلبة الحافظين للقرآن الكريم

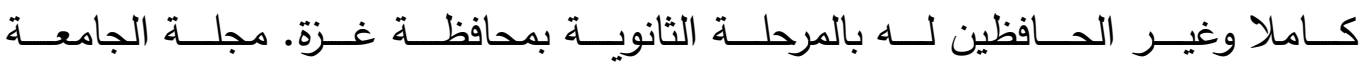

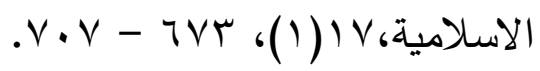

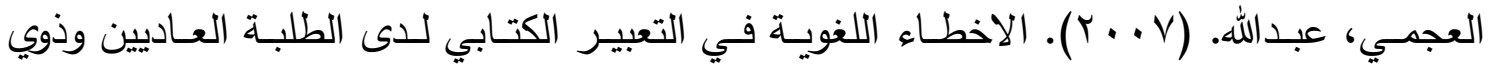
صعوبات التعلم في المرحلة المتوسطة في دولة الكويت، (رسالة ماجستير غير منشورة).

$$
\text { جامعة عمان العربية، الاردن. }
$$

عسيري، منال. (19 • ب). فاعلية اسلوب القصص التعليمية في تحسين مهارات التعبير الكتابي لاى تلميذات صعوبات التعلم. (رسالة ماجستير غير منشورة). كلية التربية، جامعة نجران. علي، عبدالهادي. (9 . . r). بعض ابعاد البنية المعرفية وأثرها على مهارات التعبير الكتابي لدى ذوي صعوبات التعلم والعاديين والمتفوقين من تلاميذ المرحلتين الابتدائية والاعدادية بمملكة

$$
\text { البحرين (رسالة ماجستير غير منشورة). جامعة الخليج العربي، البحرين. }
$$


العليان، فهد. (0 . . ץ). استراتيجية(KWL) في تدريس القراءة مفهومها، اجراءاتها، فوائدها. مجلة

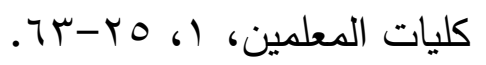

عليمـات، عاليـة. (1 ا • ץ). أثر استخدام استراتيجية التعلم ثلاثيـة KWL في اكتسـاب المفـاهيم العلمية والاحتفاظ بها في مادة العلوم للى طلبة الصف الثالث الاساسي (رسالة ماجستير غير منشورة). جامعة آل البيت، الاردن. العنزي، كوثر • (T ( • ץ). فاعلية استخدام الحاسوب فى تحسين مستوى اللغة التعبيرية الثفوية لدى الطالبات ذوات صعوبات التعلم بالمرحلة الابتدائية الحدود الثمالية (عرعر). مجلة التربية

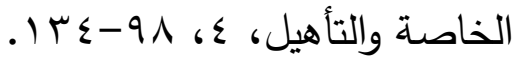

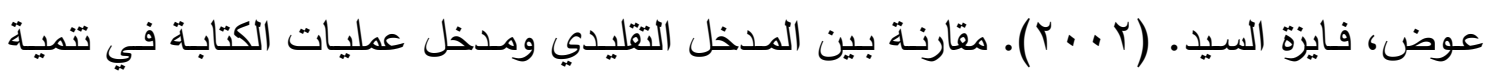
الوعي المعرفي بعملياتها وتنمية مهاراتها لدى طلاب الصف الأول الثانوي. مجلة القراءة

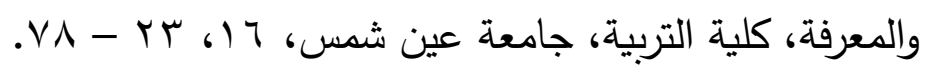

عيسى، يسري. (Y ( • Y). فاعلية برنامج تدريبي قائم على استراتيجيات التذكر في تتمية بعض مهارات التعبير الكتابي وأثره على تقدير الذات لدى عينة من تلاميذ المرحلة الابتدائية ذوي صعوبات

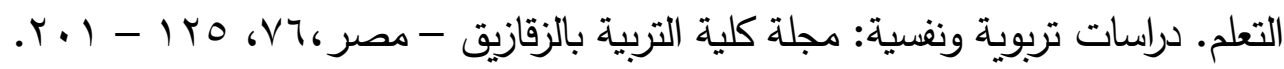

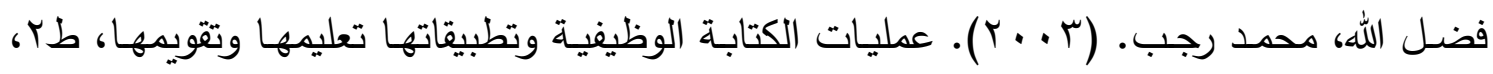

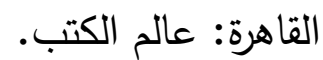
القحطاني، ماجد. (r . r). مدى توظيف معلمي اللغة العربية مهارات التعبير الكتابي في تعليمهم مقرر التعبير في المرحلة المتوسطة بمدينـة الرياض متمثلاً في نقصسان أخطائهن (رسالة ماجيستير غير منشورة). كلية التربية، جامعة الملك سعود. كابش، منال. ( • ( ب). فاعلية استراتيجية قائمة على التعلم المرتكز على المهام في ضوء نظريـة الذكاءات المتعددة في تتمية مهارات الفهم القرائي والكتابـة باللغـة الإنجليزيـة لدى طـلاب المرحلة الابتدائية (رسالة دكتوراه غير منشورة). كلية التربية، جامعة عين شمس. 
اللبودي، منى. (ع .؟). تشخيص بعض صعوبات القراءة والكتابة لدى تلاميذ المرحلة الابتدائية واستراتيجية علاجها. جامعة عين شمس، كلية التربية، الجمعية المصرية للمناهج وطرق

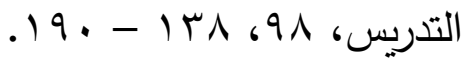

محمد، تيسير ؛ مكاوي، سيد؛ جاب الله، علي.(Y V • (Y). علاج صعوبات التعيير الكتابي الإبداعي لاى تلاميذ الصف الاول الإعدادي باستخدام التعلم المنظم ذاتيا: ورقة بحثية. مجلة بحوث

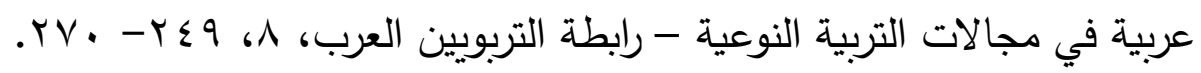

محمد، هبة. (9 ( • ( ). برنامج قائم على التكامل الحسي لتحسين التعبير الكتابي لدى الأطفال ذوي

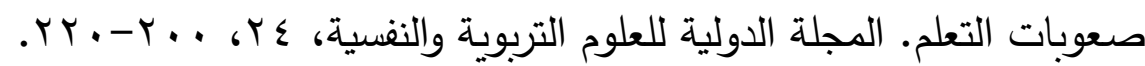

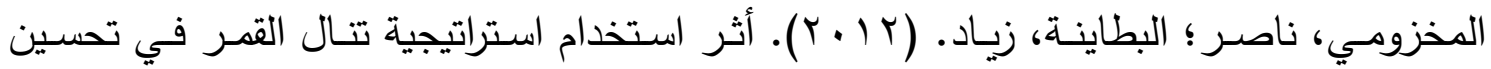
الاستيعاب القرائي والتعبير الكتابي لدى طلبة المرحلة الأساسية بالأردن. دراسات عربية في

$$
\text { التربية وعلم النفس، السعودية، } 7 \text { ب، } 09 \text { - -1. }
$$

المشايخ، فاتن. (0 1 • ب). أثر استخدام التعليم المتمايز في تحسين الفهم القرائي والتعبير الثفوي لطلبة صعوبات التعلم (رسالة ماجستير غير منشورة). جامعة عمان العربية، الاردن

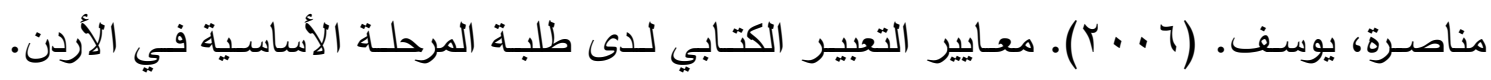

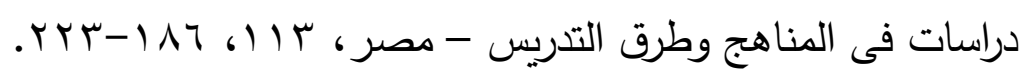

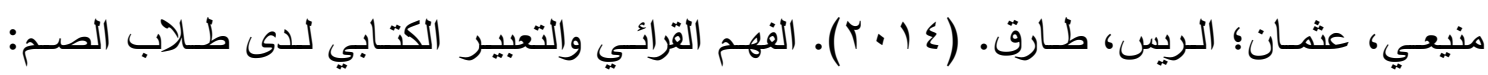
الملتحقين بكليات المؤسسة العامة للتدريب التقني والمهني في المملكة العربية السعودية:

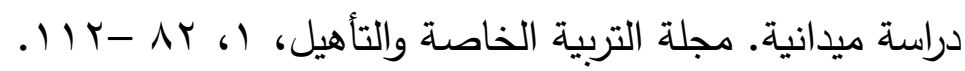
نور الدين، حاج محمد. (V V · r). صعوبات تعلم الكتابة لدى تلاميذ السنة الخامسة ابتدائي (رسالة ماجيستير غير منشورة). كلية الآداب واللغات، جامعة قاصدي مرباح- ورفلة. الوقفي، راضي. (9 · ؟). صعوبات التعلم النظري والتطبيقي. عمان: دار المسيرة. شـتوح، زهـور (1) • ب). أثر مشكلات التعلم في التحصـيل اللغـوي لـى المـتعلم مرحلـة التعليم الابتدائي. مجلة الأكاديمية للدراسات الاجتماعية والإنسانية ع 9 (، 00 - 


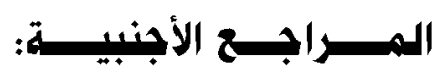

Gaon, F. (2001) A Study of Oral and Written Expression Abilities of Adolescents with Learning Disabilities, Master of Arts Thesis, Touro College.

Graham, S. (1997). Executive control in the revising of students with learning and writing difficulties. Journal of Educational Psychology, $82,223-234$.

Saddler, B . \& Asaro , K .(2007). Increasing story quality though planning and revising: Effects on young writers with writing disabilities. Learning Disability Quarterly,30, 223-234

Saddler, B. Behforooz, B. \& Asaro, K. (2008). The effects of sentence Combining instruction on the writing of fourth-grade students with writing difficulties. The Journal of special Education, (2), 24, 79 - 90.

Saddler, B.; Asaro, K. \& Behforooz, B. (2008). The effects of peer Assisted sentence - combining practice on four young writers with learning disabilities. Learning disabilities Acontempory Journal, 5(1), 17 - 31.

Tok, S. (2013). Effects of The Know-Want-Learn Strategy on Students,Mathematics Achievement, Anxiety and Metacognitive Skills. Metacognition Learning, 8,193-212.

Viel- Ruma, K. (2008). The effects of direct instruction in writing on English speakers and English language learners with disabilities (PD.D. Thesis). The college of Education, Georgia State University. Zouhor, Z., Jaskov, M., and Bogdanovic, I. (2016). The Examples of Physics Concepts Formation by The Use of KWL Strategy. The Eurasia Proceedings of Educational \& Social Sciences (EPESS), 4, 162-164. 
Lupo, Sarah M; Tortorelli, Laura; Invernizzi, Marcia; Ryoo, Ji Hoon; Strong, John Z. (2019). An Exploration of Text Difficulty and Knowledge Support on Adolescents' Comprehension. Reading Research Quarterly; Newark, 54, (4), 457-479.

Alsoudi, K. (2017). The Effect of Using K.W.L Strategy upon Acquiring Religious Concepts. World Journal of Education, 7, (2), 31-38.

İlter, İ. (2018). Exploration of Social Studies Teachers' Experiences of Reading Practices: A Phenomenological Study. The Qualitative Report; Fort Lauderdale, 23, (9), 2123-2142. 